\title{
Extratropical Transition of Hurricane Irene (2011) in a Changing Climate
}

\author{
CHUNYONG JUNG AND GARY M. LACKMANN \\ Department of Marine, Earth, and Atmospheric Sciences, North Carolina State University, Raleigh, North Carolina
}

(Manuscript received 28 August 2018, in final form 4 April 2019)

\begin{abstract}
Tropical cyclones (TCs) undergoing strong extratropical transition (ET) can produce adverse societal impacts in areas that rarely experience direct TC impacts. This, in conjunction with projected environmental changes in climatological ET regions, motivates the investigation of possible future changes in ET characteristics. We utilize a small ensemble of numerical model simulations to examine how warming affects the ET of Hurricane Irene. To assess the effects of climate change, we use the pseudo-global warming method in which thermodynamic changes, derived from an ensemble of 20 CMIP5 GCMs, are applied to analyzed initial and lateral boundary conditions of model simulations. We find increased storm intensity in the future simulations, both in reduced minimum sea level pressure and strengthened 10-m wind speed. Storm-centered composites indicate a strengthening of tropospheric potential vorticity near the center of Irene, consistent with enhanced latent heat release. The results also demonstrate that Irene's precipitation in the warmed simulations increases at a rate that exceeds Clausius-Clapeyron scaling, owing to enhanced moisture flux convergence and an additional contribution from increased surface evaporation. The duration of the transition process increased in the warmed simulations due to a weakened midtropospheric trough and reduced vertical wind shear and meridional SST gradient with a slower northward translation. These results suggest that transitioning storms may exhibit an increased ability to extend TC-like conditions poleward, and motivates additional research.
\end{abstract}

\section{Introduction}

As tropical cyclones (TCs) move out of the tropics, their interactions with the extratropical atmosphere typically lead to a loss of their tropical characteristics (Jones et al. 2003). The process by which TCs transform into extratropical cyclones is referred to as extratropical transition (ET; e.g., Klein et al. 2000; Hart and Evans 2001; Jones et al. 2003; Harr and Archambault 2016). The climatological study of Hart and Evans (2001) indicates that $\sim 46 \%$ of TCs undergo ET in the North Atlantic. While many TCs weaken upon exiting the tropics due to TC-unfavorable environmental conditions, such as low sea surface temperature (SST), increased vertical wind shear, and strengthened lower-tropospheric baroclinicity, a subset of these systems can reintensify and produce torrential precipitation, large ocean waves, and hurricane-force winds in areas that rarely experience direct TC impacts. For example, Hurricane Floyd (1999) brought very heavy precipitation and catastrophic flooding along the U.S. East Coast. The extent and

\footnotetext{
Corresponding author: Chunyong Jung, cyjung07@gmail.com
}

intensity of the precipitation distribution accompanying Floyd were governed by the interaction between the extratropically transitioning Floyd and a midlatitude trough (Atallah and Bosart 2003; Colle 2003). The highly destructive Sandy (2012) underwent several intensity changes during its life cycle (Galarneau et al. 2013; Shin and Zhang 2017); Galarneau et al. (2013) showed that the final intensification of Sandy was closely related to its ET process. Generally, TCs undergoing strong ET can produce adverse societal impacts in areas far removed from the original TCs, such as Canada, Europe, or the northeastern United States; these areas are both densely populated and are not accustomed to such events. In recognition of the importance of ET events, numerous studies have been devoted to TCs undergoing ET (e.g., Klein et al. 2000, 2002; Atallah and Bosart 2003; Abraham et al. 2004; Kitabatake 2008, 2011; Beven 2012a,b). A synthesis of fundamental ET understanding and direct and indirect ET impacts are described in the reviews of Jones et al. (2003), Evans et al. (2017), and Keller et al. (2019).

Owing in part to their societal importance, numerous studies have also examined how climate change would 
affect the frequency and intensity of TCs (e.g., Emanuel 1988; Knutson and Tuleya 1999; Knutson et al. 2001; Knutson and Tuleya 2004; Oouchi et al. 2006; Bengtsson et al. 2007; Vecchi and Soden 2007; Bender et al. 2010; Hill and Lackmann 2011). Several of these studies identify an increase in the frequency of very intense (e.g., category 4 and 5) hurricanes under climate warming based on projected climate change by late in the twenty-first century. However, only a few studies have considered the question of how climate change will affect the characteristics of recurving TCs, and TCs undergoing ET (see Evans et al. 2017, their section 3e).

How and why would we expect ET events to change with warming? First, TC-favorable environmental changes, such as increased SST and reduced vertical wind shear, are projected for the North Atlantic during the latter half of the twenty-first century (e.g., Liu et al. 2017). The study of Liu et al. (2017) examined future changes in ET activity using a climate model, finding that ET occurrence may increase in the eastern North Atlantic. Previous studies demonstrate that a projected tropical upper-tropospheric warming maximum would mitigate TC intensification with warming, reducing intensity increases relative to what would occur with a uniform vertical warming profile (e.g., Shen et al. 2000; Hill and Lackmann 2011). However, as TCs move poleward, they may become spatially separated from the region of greatest upper-tropospheric warming, leading to our motivating hypothesis that TCs undergoing ET may exhibit greater relative strengthening with warming compared to TCs remaining in the tropics, or that they may increasingly maintain their strength as they move poleward in warmer environments.

Few studies have investigated the dynamical, stormscale changes in ET with warming. Studies based on general circulation models (GCMs) do not adequately capture TCs in general, and thus are limited in their ability to describe changes in ET with warming. Here, we investigate changes in storm-scale characteristics and hazards accompanying an ET event with warming using a high-resolution nonhydrostatic model. In this study, we investigate future changes in the characteristics of an individual TC, Irene (2011), using the Advanced Research version of the Weather Research and Forecasting (WRF-ARW) Model, analyzing stormscale structural changes during ET in both presentday and warmed environments. We selected Hurricane Irene (2011) because it represents a strong ET event that produced considerable societal impacts associated with heavy precipitation along the U.S. East Coast and in New England, including extreme flooding in central and southern Vermont. Furthermore, initial control simulations matched reasonably well with the observed track and intensity. Other ongoing work is examining the effects of warming on a larger sample of ET events, but it is informative to examine storm-scale changes of a single event.

Irene formed on 15 August 2011 off the coast of West Africa as a tropical storm and tracked westward while undergoing steady intensification (Avila and Cangialosi 2011). On 25 August, Irene recurved near $75^{\circ} \mathrm{W}, 25^{\circ} \mathrm{N}$ to a north-northeastward track, and four days later underwent ET. Irene merged with a frontal system on 30 August as it transitioned to an extratropical cyclone. Based on previous studies that identified considerable sensitivity of simulated TC intensity and structure to physics parameterization choices (e.g., Braun and Tao 2000; Davis and Bosart 2002; Hill and Lackmann 2009a), we use a small ensemble of simulations with varying precipitation physics and planetary boundary layer parameterizations to allow for more robust results.

In section 2, we discuss the motivation for and limitations of our methods. Section 3 compares our present-day simulations to observations, and section 4 presents changes in the Irene ET event with warming. A discussion and summary are provided in section 5 .

\section{Experimental design and methods}

\section{a. Numerical model experimental design and present- day simulations}

We ran small ensembles consisting of seven members, varying microphysics, cumulus parameterization, and boundary layer physics, using WRF model version 3.9 (Skamarock et al. 2008). The use of small ensembles allows us to obtain more robust results than could be obtained by comparing individual simulations (e.g., Hill and Lackmann 2011; Lackmann 2015; Taniguchi 2018). Ancell et al. (2018) demonstrate that the interpretation of perturbation experiments, which change initial condition or other model aspects, can be significantly contaminated by the rapid, unrealistic propagation of numerical noise. The use of small ensembles also helps us to address such challenges in the interpretation of simulation comparisons.

Each simulation is of 228-h duration, initialized at 0000 UTC 23 August 2011 with 15-km horizontal grid spacing and 49 vertical levels. Data obtained from the NCEP Climate Forecast System version 2 (CFSv2; Saha et al. 2014) 6-hourly reanalysis, available with an approximate grid length of $0.5^{\circ}$, and daily Real-Time Global SST analyses (RTG_SST) at $0.5^{\circ}$ horizontal 
TABLE 1. Summary of WRF Model experiments. The experiments are classified as present-day, future, partially idealized present-day, and partially idealized future simulations. The cumulus parameterization (CP) scheme choices include Kain-Fritsch (KF) and Tiedtke. The microphysics (MP) choices include the WRF single-moment 6-class microphysics scheme (WSM6), the Morrison scheme, the Goddard scheme, and the WRF double-moment 6-class microphysics scheme (WDM6). The planetary boundary layer (PBL) and TC flux column includes the use of the Yonsei University (YSU) scheme and Mellor-Yamada-Janjić (MYJ) scheme; the TC flux correction option was utilized in only two (i.e., runs 6 and 7) experiments. All simulations used the DFI option, 49 dry-air sigma model levels, and a model top of $50 \mathrm{hPa}$.

\begin{tabular}{|c|c|c|c|c|c|}
\hline \multirow{2}{*}{$\frac{\text { Run }}{1}$} & \multicolumn{2}{|c|}{ Types of experiment } & \multirow{2}{*}{$\frac{\text { CP scheme }}{\mathrm{KF}}$} & \multirow{2}{*}{$\begin{array}{c}\text { Microphysics } \\
\text { WSM6 }\end{array}$} & \multirow{2}{*}{$\frac{\text { PBL/TC flux }}{\text { YSU/no }}$} \\
\hline & Real orography & Present day/Future & & & \\
\hline & Partially idealized (ocean covered) & Present day/Future & & & \\
\hline \multirow[t]{2}{*}{2} & Real orography & Present day/Future & Tiedtke & WSM6 & YSU/no \\
\hline & Partially idealized (ocean covered) & Present day/Future & & & \\
\hline \multirow[t]{2}{*}{3} & Real orography & Present day/Future & $\mathrm{KF}$ & WSM6 & $\mathrm{MYJ} /$ no \\
\hline & Partially idealized (ocean covered) & Present day/Future & & & \\
\hline \multirow[t]{2}{*}{4} & Real orography & Present day/Future & $\mathrm{KF}$ & Goddard & YSU/no \\
\hline & Partially idealized (ocean covered) & Present day/Future & & & \\
\hline \multirow[t]{2}{*}{5} & Real orography & Present day/Future & $\mathrm{KF}$ & WDM6 & YSU/no \\
\hline & Partially idealized (ocean covered) & Present day/Future & & & \\
\hline \multirow[t]{2}{*}{6} & Real orography & Present day/Future & KF & Morrison & YSU/yes \\
\hline & Partially idealized (ocean covered) & Present day/Future & & & \\
\hline \multirow[t]{2}{*}{7} & Real orography & Present day/Future & $\mathrm{KF}$ & WSM6 & YSU/yes \\
\hline & Partially idealized (ocean covered) & Present day/Future & & & \\
\hline
\end{tabular}

grid length are utilized for initial and boundary conditions. All simulations employ the WRF digital filter initialization (DFI) procedure, which balances the wind and mass fields at the initial time using adiabatic backward and diabatic forward time integration (e.g., Lynch and Huang 1992). Model physics choices include the Rapid Radiative Transfer Model-Global (RRTMG) scheme for longwave and shortwave radiation, the Noah land surface model, and varying convective, planetary boundary layer, and microphysics schemes (Table 1).

Analysis of our initial experiments revealed significant differences in the track between present-day and warmed simulations, resulting in differences in landfall timing and location. We sought to minimize differences in such land interactions, which are highly case-specific, in favor of a focus on ET response to thermodynamic changes. However, we wished to retain the case-specific synoptic pattern accompanying Irene, which was optimal for a realistic analysis of the ET process. Thus in addition to experiments employing realistic orography, we conducted a set of partially idealized experiments with no orography and entirely oceanic domains. In grid cells formerly occupied by land, we compute the SST using an equation describing the functional form of the variation of SST in the aqua-planet experiments proposed by Neale and Hoskins (2000),

$$
\operatorname{SST}_{\mathrm{NH}}(\lambda, \phi)=27\left[1-\sin ^{4}\left(\frac{3 \phi}{2}\right)\right]{ }^{\circ} \mathrm{C} ;-\frac{\phi}{3}<\phi<\frac{\phi}{3},
$$

where $\lambda$ is the longitude and $\phi$ is the latitude. Since their experiments were fully idealized, the observed SST is not considered in (1); accordingly, we modify this expression to reflect the observed SST:

$$
\operatorname{SST}_{\mathrm{rev}}(\lambda, \phi)=\left\{\begin{array}{c}
\overline{\operatorname{SST}\left(\phi_{0}\right)}\left[1-\sin ^{4}\left(\frac{3 \phi}{2}\right)\right]{ }^{\circ} \mathrm{C} \operatorname{SST}_{\mathrm{NH}}(\lambda, \phi) \geq \overline{\operatorname{SST}(\phi)} \\
\overline{\operatorname{SST}\left(\phi_{0}\right)} \\
; \operatorname{SST}_{\mathrm{NH}}(\lambda, \phi)<\overline{\operatorname{SST}(\phi)}
\end{array}\right\},
$$

where $\phi_{0}$ is the lowest latitude in the experimental domain, the overbar depicts a zonal average over the model domain, SST is the analyzed SST, and SST $_{\text {rev }}$ is the revised value obtained via (2). Thus, for grid cells that were previously land, we have created a new $\mathrm{SST}_{\text {rev }}$ field that does not vary with longitude, with values reasonable for a given latitude, and which smoothly blends to the analyzed oceanic SST values (Fig. 1). Based on the above experimental configuration, four types of subexperiments are designed in each set of sensitivity simulations to examine future changes in characteristics of the extratropically transitioning Irene: 

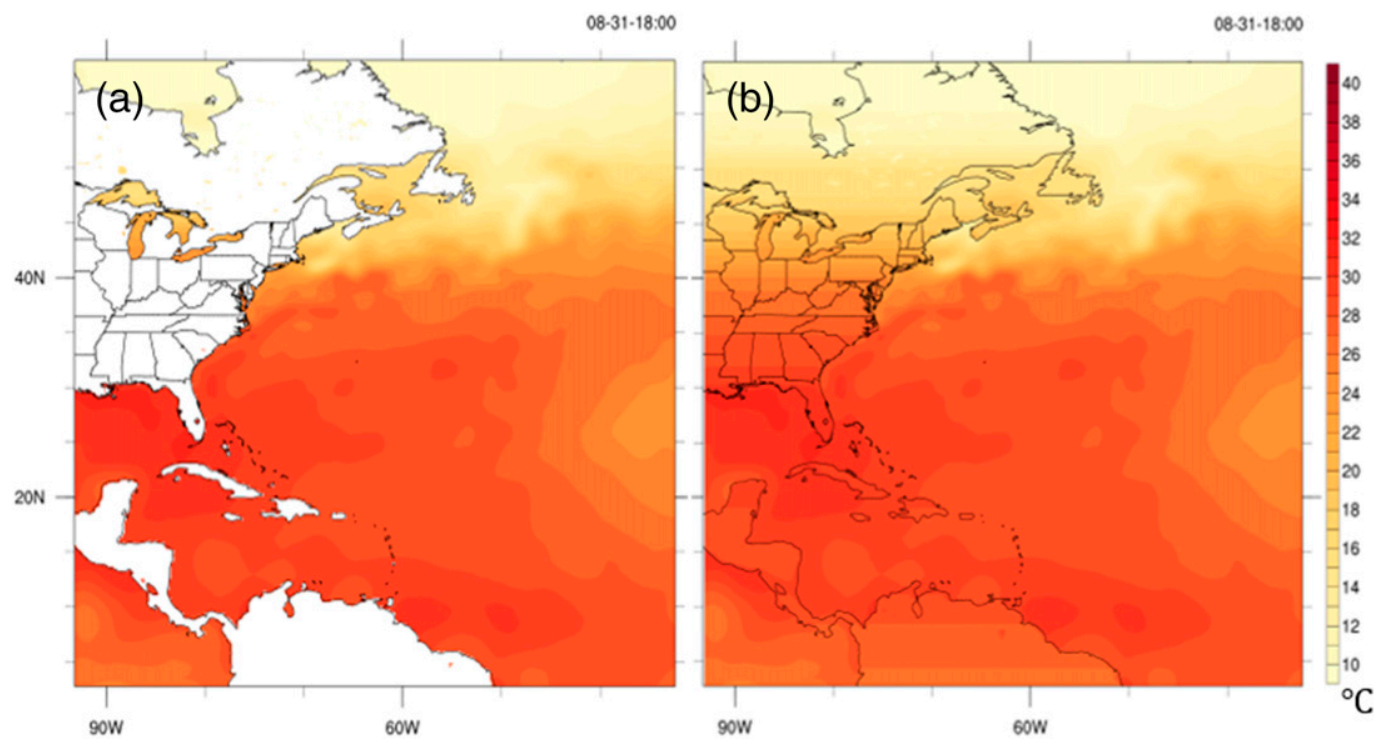

FIG. 1. Sea surface temperature $\left({ }^{\circ} \mathrm{C}\right)$ in (a) realistic orography environment and (b) partially idealized ocean-only experiments at the initial time of the present-day simulation, 0000 UTC 23 Aug 2011.

present-day with realistic orography, future with realistic orography, partially idealized present-day, and partially idealized future (Table 1).

\section{b. Future simulations: PGW method}

We computed thermodynamic changes from a $20-$ model ensemble of GCMs from phase 5 of the Coupled Model Intercomparison Project (CMIP5). We utilized output from the representative concentration pathway (RCP) 8.5 scenario to compute "delta" values for temperature, and applied these to the initial and boundary conditions in accordance with a pseudo-global warming (PGW) approach (Frei et al. 1998; Sato et al. 2007; Rasmussen et al. 2011; Mallard et al. 2013; Jung et al. 2015). Mizuta et al. (2014) used cluster analysis to identify three distinct patterns of SST change in CMIP5

TABLE 2. List of 20 CMIP5 GCMs adopted in this study for computation of "delta" fields, applied in the PGW approach.

\begin{tabular}{|c|c|c|}
\hline Model & Modeling center/group & Grid length \\
\hline $\begin{array}{l}\text { ACCESS1.0 } \\
\text { ACCESS1.3 }\end{array}$ & $\begin{array}{l}\text { Commonwealth Scientific and Industrial Research Organization (CSIRO) and Bureau of } \\
\text { Meteorology (BOM), Australia }\end{array}$ & $1.25^{\circ} \times 1.875^{\circ}$ \\
\hline CanESM2 & Canadian Centre for Climate Modeling and Analysis & $2.8^{\circ} \times 2.8^{\circ}$ \\
\hline CMCC-CM & $\begin{array}{l}\text { Centro Euro-Mediterraneo sui Cambiamenti Climatici (Euro-Mediterranean Center on } \\
\text { Climate Change) }\end{array}$ & $0.8^{\circ} \times 0.8^{\circ}$ \\
\hline CNRM-CM5 & National Centre of Meteorological Research, France & $1.4^{\circ} \times 1.4^{\circ}$ \\
\hline GISS-E2-H & NASA Goddard Institute for Space Studies & $2^{\circ} \times 2.5^{\circ}$ \\
\hline \multicolumn{3}{|l|}{ GISS-E2-H-CC } \\
\hline HadGEM2-AO & Met Office Hadley Centre & $1.25^{\circ} \times 1.875^{\circ}$ \\
\hline \multicolumn{3}{|l|}{ HadGEM2-ES } \\
\hline INM-CM4 & Institute for Numerical Mathematics & $1.5^{\circ} \times 2^{\circ}$ \\
\hline IPSL-CM5A-MR & Institut Pierre Simon Laplace, France & $1.25^{\circ} \times 2.5^{\circ}$ \\
\hline IPSL-CM5B-LR & & $1.8^{\circ} \times 2.75^{\circ}$ \\
\hline MIROC-ESM & Japan Agency for Marine-Earth Science and Technology, Atmosphere and Ocean Research & $2.8^{\circ} \times 2.8^{\circ}$ \\
\hline MIROC-ESM-CHEM & Institute (The University of Tokyo), and National Institute for Environmental Studies & \\
\hline MPI-ESM-LR & Max Planck Institute for Meteorology & $1.8^{\circ} \times 1.8^{\circ}$ \\
\hline \multicolumn{3}{|l|}{ MPI-ESM-MR } \\
\hline MRI-ESM1 & Meteorological Research Institute, Japan & $1.1^{\circ} \times 1.1^{\circ}$ \\
\hline NorESM1-M & Norwegian Climate Center, Norway & $1.9^{\circ} \times 2.5^{\circ}$ \\
\hline NorESM1-M & & \\
\hline
\end{tabular}



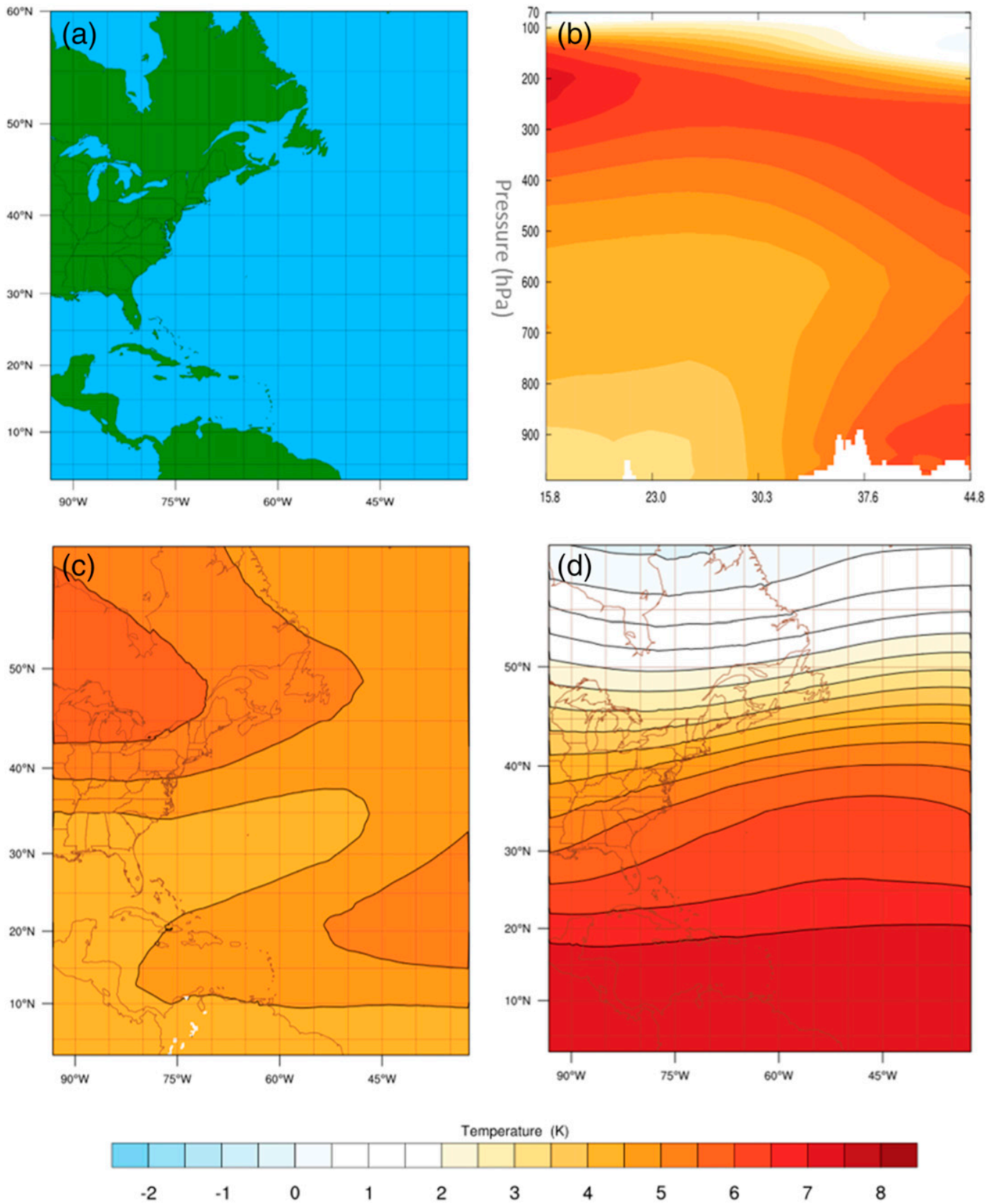

FIG. 2. (a) WRF model domain employed in present-day and future simulations and (b) ensemble meridional cross section of imposed temperature change $(\mathrm{K})$ along the $80^{\circ} \mathrm{W}$ longitude band from $15^{\circ}$ to $45^{\circ} \mathrm{N}$ at initial time of simulation. (c),(d) As in (b), but for composite temperature change (K) at the 700- and 200-hPa level, respectively.

GCM projections; use of these differing SST change patterns would yield differences in our future simulations. However, previous studies have found that simulated changes in idealized future TC intensity and structure are not highly sensitive to large-scale GCM changes, given the temporal averaging used and relatively short duration of the model integration (Hill and Lackmann 2011; Lackmann 2015). Lackmann (2015) examined the variability associated with change fields computed from individual GCMs and compared this to results with ensemble-mean changes, and found that increased ensemble spread was evident but the mean changed little. Although it would provide insight to explore responses based on different GCM projection clusters and emission scenarios, in this investigation we restrict consideration to a $20-\mathrm{GCM}$ ensemble mean for 

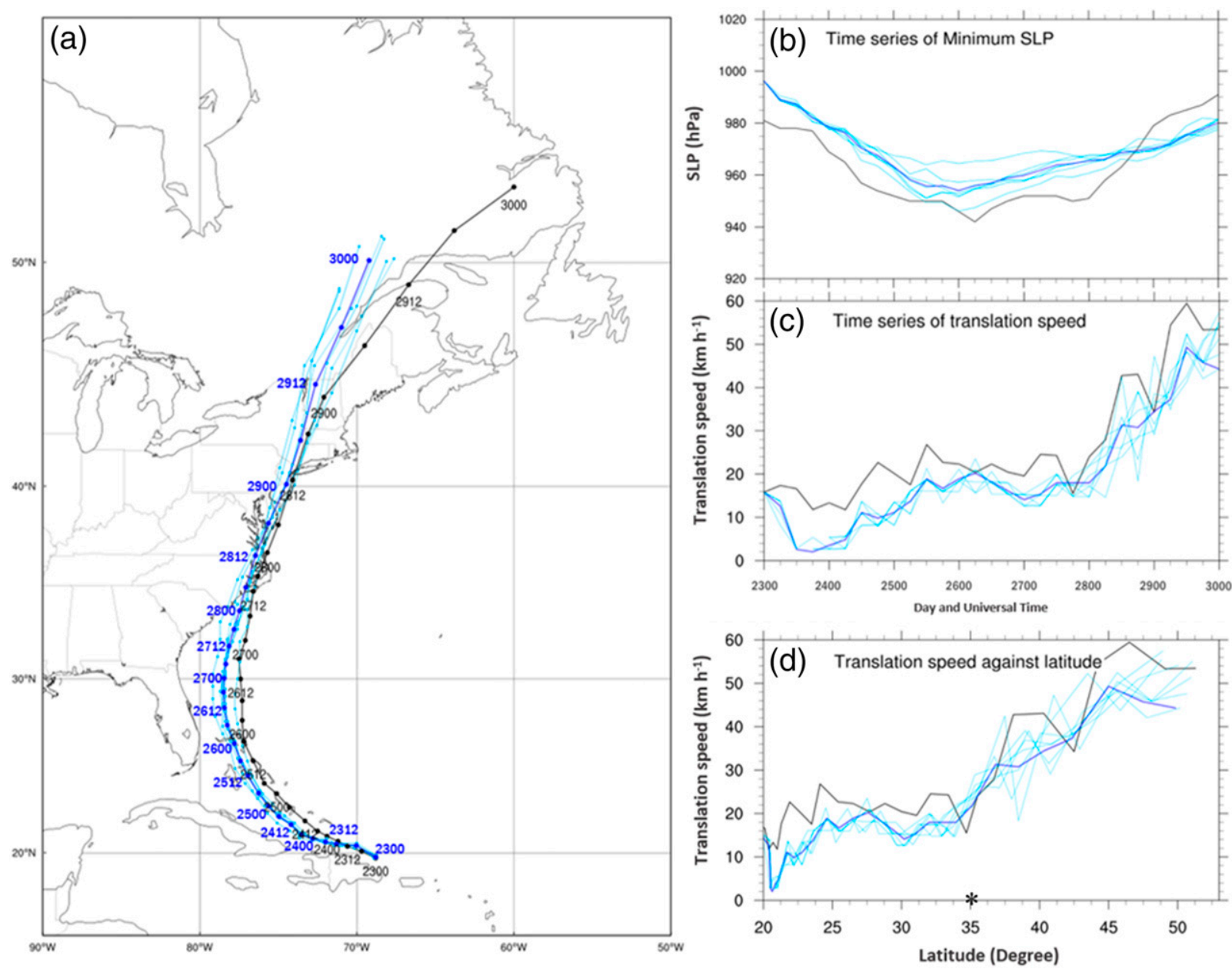

FIG. 3. Present-day ensemble comparison to observations for (a) track, (b) minimum sea level pressure (hPa), (c) time series of translation speed $\left(\mathrm{km} \mathrm{h}^{-1}\right)$, and $(\mathrm{d})$ translation speed against latitude $\left(\mathrm{km} \mathrm{h}^{-1}\right)$. Black lines indicate values derived from HURDAT2 observations. The thicker blue lines represent the ensemble mean and thin light blue lines depict individual ensemble members. The latitude of precipitation maxima in North Carolina is represented by an asterisk.

future RCP8.5 SST change projections in generating our future PGW ensemble (Table 2). By keeping relative humidity constant and applying warming, we indirectly impose an increase in water vapor content that is consistent with the existing synoptic weather pattern. Then, using the modified virtual temperature profile, we compute the hydrostatically balanced geopotential height field. A more detailed description of the PGW method is provided below.

We compute monthly averages of thermodynamic quantities, including 2-m air temperature, SST, surface and soil temperature, and atmospheric temperature at isobaric levels over a 20-yr period from 1980 to 1999 for the CMIP5 historical ensemble. We then used a similar process for the period from 2080 to 2099 for the future GCM ensemble. Next, these averaged fields on varying spatial grids were bilinearly interpolated to the $0.5^{\circ} \mathrm{CFSv} 2$ grid. We then applied the 20 -yr regridded average thermodynamic changes to CFSv2 initial and boundary conditions, corresponding to large-scale thermodynamic conditions in the late twenty-first century,

TABLE 3. Root-mean-square error (RMSE) for each ensemble member in present-day simulation in terms of minimum sea level pressure $(\mathrm{hPa})$ and cyclone track $(\mathrm{km})$ in comparison to HURDAT2.

\begin{tabular}{ccc}
\hline \hline Case & $\begin{array}{c}\text { Minimum sea level } \\
\text { pressure }(\mathrm{hPa})\end{array}$ & $\begin{array}{c}\text { Cyclone } \\
\text { track }(\mathrm{km})\end{array}$ \\
\hline 1 & 10.3 & 55.2 \\
2 & 13.8 & 60.4 \\
3 & 8.3 & 60.9 \\
4 & 10.9 & 80.9 \\
5 & 12.0 & 53.2 \\
6 & 10.3 & 83.3 \\
7 & 9.6 & 56.2 \\
Ensemble & 10.8 & 64.3 \\
\hline
\end{tabular}



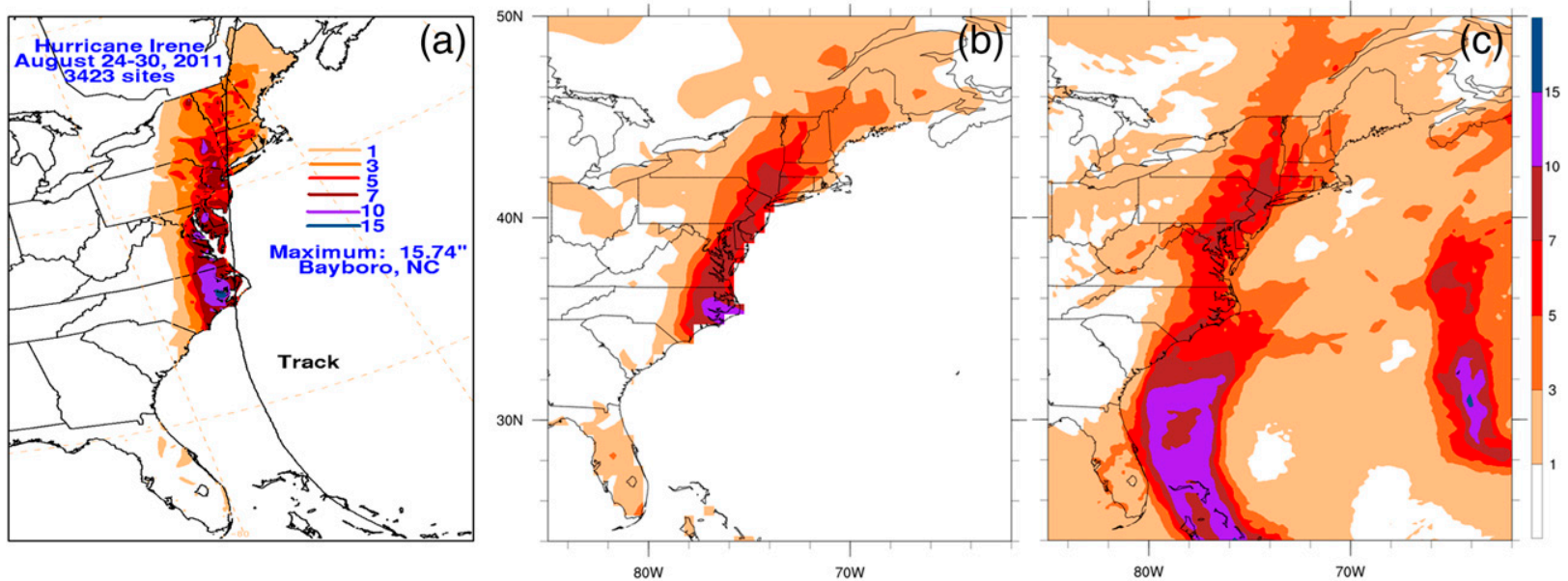

FIG. 4. Accumulated precipitation (shading; in.) ranging from 0000 UTC 24 Aug through 0000 UTC 30 Aug 2011 derived from (a) Weather Prediction Center tropical cyclone rainfall data, (b) Climate Prediction Center precipitation analysis, and (c) present-day WRF ensemble mean.

but with a synoptic pattern that is nearly identical to that which preceded Hurricane Irene. The RRTMG radiation scheme $\mathrm{CO}_{2}$ concentration is also adjusted to $936 \mathrm{ppm}$, which is consistent with the value projected by RCP8.5 for 2100 (Meinshausen et al. 2011).
These updated initial and boundary conditions enable us to isolate the influences resulting from climate warming on future changes in characteristics of Irene in a synoptic environment that is highly similar to that observed. Even though we directly impose the thermodynamic changes on
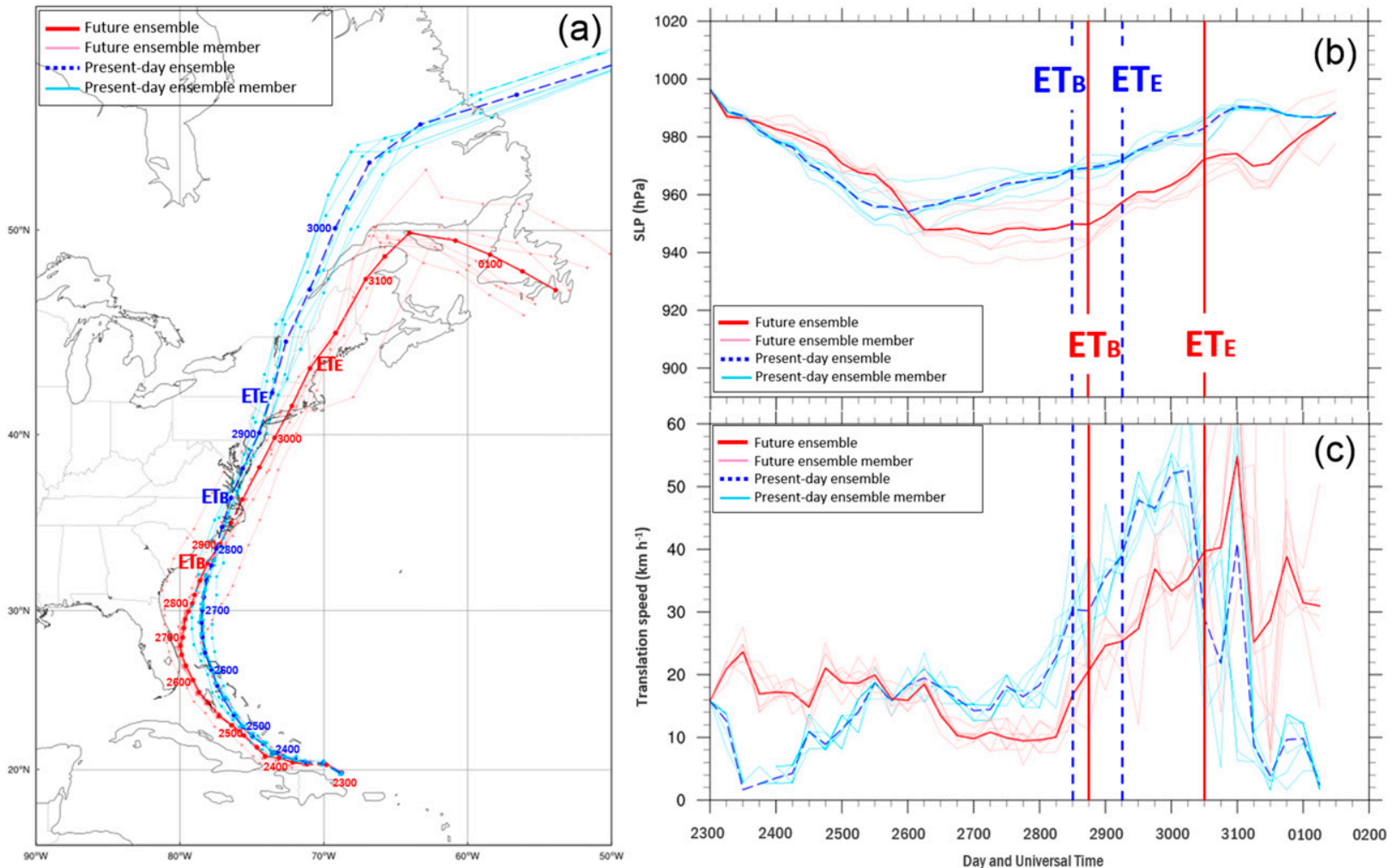

FIG. 5. Future ensemble comparison to present-day ensemble mean for (a) track, (b) intensity, and (c) translation speed in realistic orography experiments. The dark blue dashed lines represent the present-day ensemble and the dark red solid lines represent the future ensemble. The onset and completion of ensemble $\mathrm{ET}$ are labeled $\mathrm{ET}_{B}$ for the onset and $\mathrm{ET}_{E}$ for the completion of transition. 

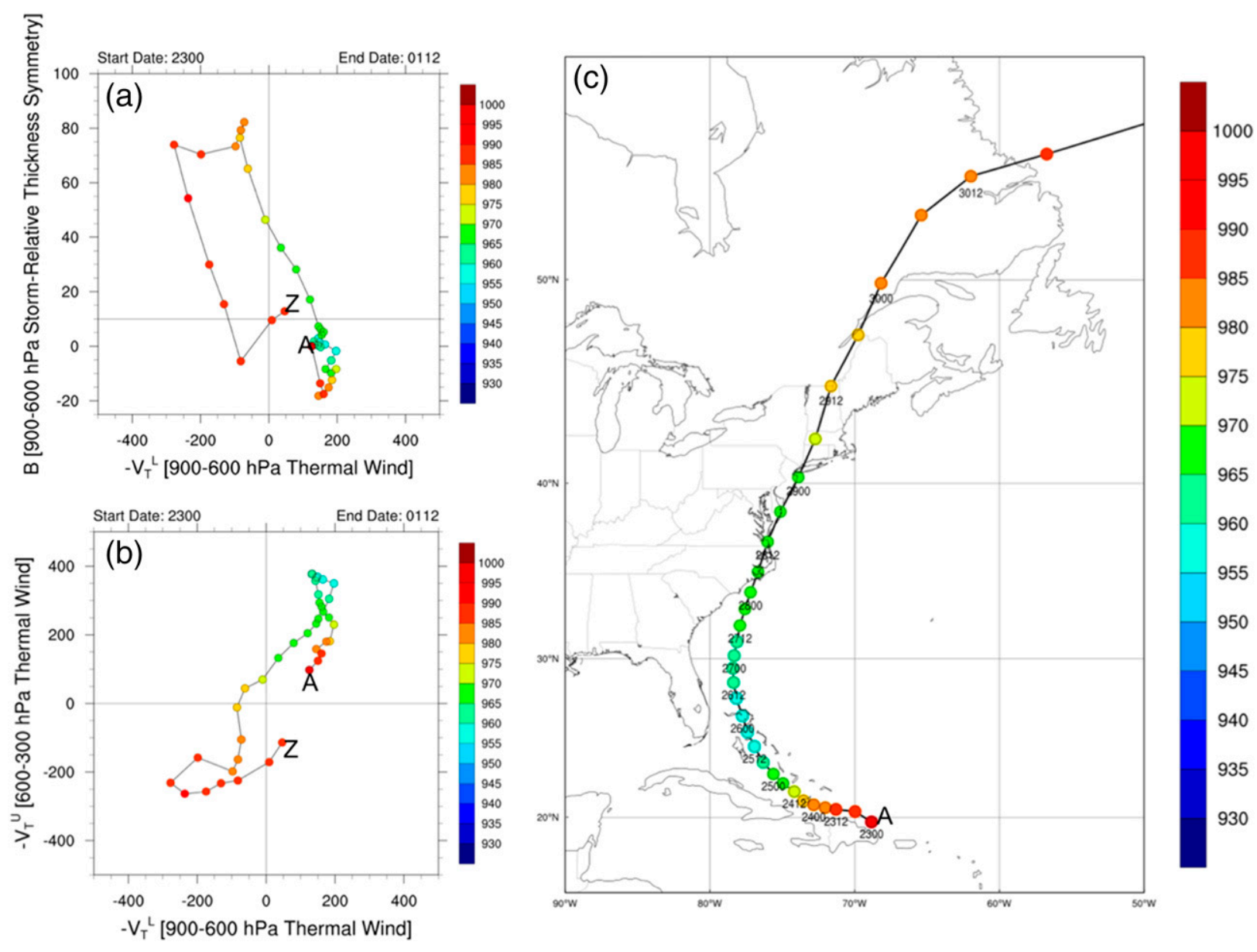

FIG. 6. (a),(b) The cyclone phase space (CPS) diagrams and (c) track for the present-day ensembles in simulations with realistic orography. Values are plotted every $6 \mathrm{~h}$ with color markers indicating the minimum sea level pressure (hPa) of the storm. The letters $\mathrm{A}$ and $\mathrm{Z}$ indicate the starting and end of the storm life cycle, respectively. Note that $-V_{T}^{L}>0$ indicates a lower warm-core structure in (a) and (b).

the current synoptic environment, the synoptic pattern in the future is not exactly identical to the current one since the model simulation is allowed to evolve dynamically for the duration of the event. In other words, the changes resulting from the imposing the thermodynamic alterations can include dynamical changes as well (Lackmann 2013). We contend that it is reasonable to assume that a similar synoptic pattern to that accompanying Hurricane Irene could plausibly occur in the future.

In accordance with previous studies (e.g., Allen and Ingram 2002; Soden et al. 2005; Wentz et al. 2007; Hill and Lackmann 2011), relative humidity is held constant in this study, leading to increased water vapor mixing ratio in warmed areas, consistent with the ClausiusClapeyron relation. The temperature changes at the initial time are consistent with the large-scale GCMbased changes (Figs. 2b-d). When the modified data imposed by thermodynamic changes are run through the
WRF preprocessing system (WPS), geopotential height is recalculated based on the increased virtual temperature, leading to some imbalance between mass and wind fields. Although some previous studies (e.g., Lackmann 2013; Marciano et al. 2015) found that the imbalance arising from the imposed change is generally small enough to avoid generation of strong gravity waves in the simulation, we use the DFI feature to ensure balance and to generate cloud and hydrometeor fields at the initial time.

An advantage of the PGW method is the ability to simulate high-impact weather events at sufficient resolution to capture many of the key dynamical processes, without incurring intractable computational expense. Several of the important limitations of this method are discussed at length by Lackmann (2015) and others, notably that this method does not provide information regarding changes in the frequency of this type of event. Still, the use of PGW, which represents a "storyline" 

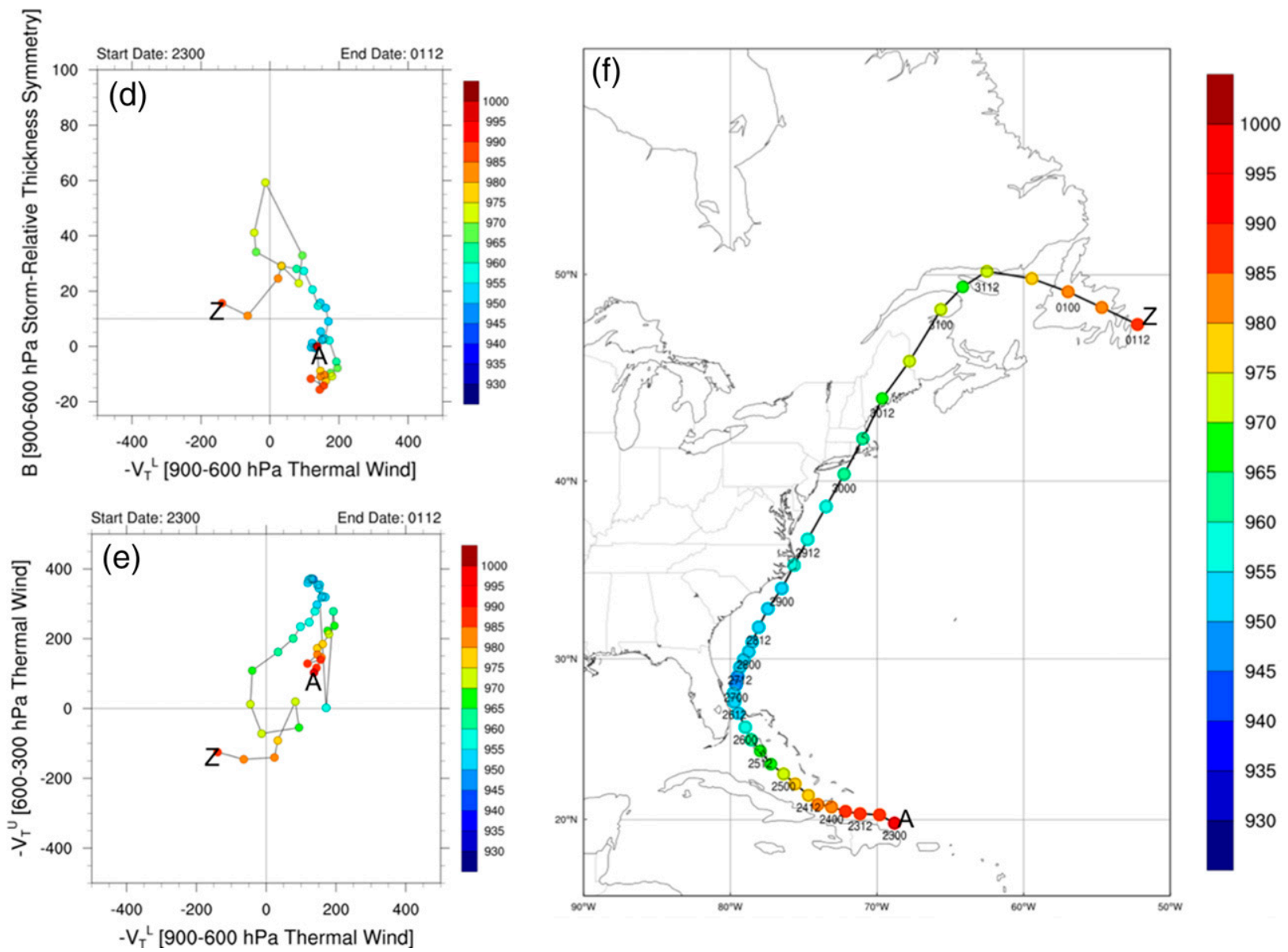

FIG. 6d-f. As in (a)-(c), but for future ensembles.

approach in the nomenclature of Shepherd (2016), can be viewed in conjunction with other approaches to provide a more complete picture of possible future changes in extreme events than could be derived from low-resolution GCM simulations alone (Trenberth et al. 2015; Hazeleger et al. 2015; Shepherd 2016; Lloyd and Oreskes 2018).

\section{c. Determination of the onset and completion of ET}

We adopt the definition of onset and completion of ET presented by Hart (2003) and Evans and Hart (2003) in this study. In cyclone phase space (CPS), four parameters, including the difference in $900-600-\mathrm{hPa}$ geopotential thickness between the right and left sides of the TC relative to its direction of motion $(B)$, low-level thermal wind between 900 and $600 \mathrm{hPa}\left(-V_{T}^{L}\right)$, and upper-level thermal wind between 600 and $300 \mathrm{hPa}$ $\left(-V_{T}^{U}\right)$ are utilized to describe a TC. The onset of ET is defined as the time when values of $B$ exceed $10 \mathrm{~m}$, which was defined as a threshold for the "asymmetric warm core" in the CPS (Hart 2003) implying significant asymmetry; the completion of ET is defined as the time when the lower-tropospheric thermal wind indicates a cold core (i.e., $-V_{T}^{L}<0$ ).

\section{d. Storm-centered compositing}

To assess storm-scale changes in intensity, wind speed, storm structure, and precipitation in a warming climate during ET, we use storm-centered compositing. Using the defined onset and completion of ET, storm-centered coordinates enable direct comparison of the evolution between future and present-day characteristics of Irene. A $750 \mathrm{~km} \times 750 \mathrm{~km}$ grid box is centered on the grid cell of minimum sea level pressure (SLP) in each simulation, allowing creation of a storm-centric coordinate system. Finally, we average all the storms extracted from each ensemble member, and present these in storm-centered coordinates. Given their similar tracks, we did not deem it necessary to rotate storms relative to their travel path. Since the experimental domain of this study is designed to examine the ET period of Irene, the composite analysis is confined to the ET period to avoid possible 
contamination from the lateral boundaries. The size of the storm-centered grid (i.e., $750 \mathrm{~km} \times 750 \mathrm{~km}$ ) is the maximum grid size possible without appreciable lateral boundary contamination.

\section{Evaluation of present-day simulations}

We superimpose the WRF ensemble mean and individual tracks and SLP minima on HURDAT2 (Landsea and Franklin 2013) in Fig. 3. In addition, we compute the root-mean-square error (RMSE) to assess quantitatively the performance of present-day simulations for SLP minima and track for each present-day simulation against the HURDAT2 (Table 3). Owing to the relatively coarse resolution of the CFSv2 initial condition data, the simulated ensemble mean Irene is initialized with a minimum SLP $\sim 15 \mathrm{hPa}$ higher than observed. The reanalysis data systematically underestimate observed TC intensity and this may be justified because the horizontal grid spacing is still too coarse to resolve observed TC intensity (Gentry and Lackmann 2010; Murakami 2014). Even though the minimum SLP RMSE for most of the individual simulations is around $10 \mathrm{hPa}$ and the simulated ensemble mean storm propagates slower than the observed over the entire simulation, the ensemble mean reproduces the deepening and weakening stages of Irene (Fig. 3b). Furthermore, most of the individual simulations exhibit a track RMSE of less than $80 \mathrm{~km}$, which is comparable to the official NHC $36-\mathrm{h}$ forecast track error of $\sim 83 \mathrm{~km}$ (Avila and Cangialosi 2011).

Gauge-based observational analyses of total accumulated precipitation, obtained from the Weather Prediction Center for the 144-h period ending 0000 UTC 30 August, reveal that Hurricane Irene produced heavy rainfall along its track over the East Coast, bringing significant flooding to parts of North Carolina, and New England (Fig. 4a). As an additional check, we also used the NOAA Climate Prediction Center (CPC) gaugebased analysis data for comparison (Xie et al. 2007; Chen et al. 2008). Although the intensity of precipitation differs slightly among the analyses, the overall spatial precipitation patterns are consistent with each other. Even though the corresponding present-day ensemble simulation had a similar spatial pattern of precipitation to the observational analyses, the simulated ensemble mean precipitation is lighter than analyzed along the track over the East Coast, particularly in eastern North Carolina. Ensemble mean precipitation in parts of New England was underdone as well. A difference in translation speed between the observed $\left(21 \mathrm{~km} \mathrm{~h}^{-1}\right)$ and simulated $\left(27 \mathrm{~km} \mathrm{~h}^{-1}\right)$ storm while passing over eastern North Carolina likely contributed to the underestimation of simulated precipitation there between 0600 and 1800 UTC 28 August (Figs. 3c,d). Overall the simulated translation speed of Irene was slower than observed (Figs. 3a,c), so other factors were responsible for precipitation differences in New England. We speculate that a slight westward track shift in several ensemble members relative to the observed track is consistent with a reduction in orographic precipitation over the mountainous terrain in this region. Despite these differences, the precipitation distribution associated with the storm is sufficiently similar between observation and simulation, with a pattern correlation coefficient of 0.83 with the CPC analysis. Further, our focus relies primarily on partially idealized simulations without land or orography, for which an observational comparison is not possible.

\section{Projected future changes and analysis}

\section{a. Intensity}

We begin our assessment of future changes of Irene with the realistic orography simulations. The future ensemble mean of Irene attains a peak minimum SLP $\sim 8.5 \mathrm{hPa}$ deeper than that found in the present-day ensemble mean (Fig. 5b). CPS diagrams indicate that the ET process differed between present-day and future simulations, with a tendency for the future system to exhibit a stronger warm core (Fig. 6). The latitude of maximum intensity is farther poleward in the future simulations, a result that is consistent with the findings of Kossin et al. (2014). The future ensemble mean also exhibits a maximum 12 -h deepening rate that is $\sim 40 \%$ greater than that of the present-day ensemble. However, the minimum SLP, as with precipitation, tends to be highly influenced by the TC track; it is clear from Figs. 5a and $5 \mathrm{~b}$ that the present-day and future simulations exhibited substantially different tracks, and thus experienced different degrees of land interaction. The future ensemble mean track indicates interaction with Florida early in the model integration, but then shifted east of the present-day storm later in its life cycle. The future simulations generally featured a slower translation speed than the present-day simulations during the middle portion of the simulations, but was faster in the early and later portions of the simulations (Fig. 5c). Owing to track differences, it is difficult or impossible to disentangle changes due to differing land interactions from those due to large-scale thermodynamic changes.

Due to the aforementioned track differences, we conducted an additional set of partially idealized experiments with no orography and an entirely oceanic domain (see section 2a) in order to minimize changes 

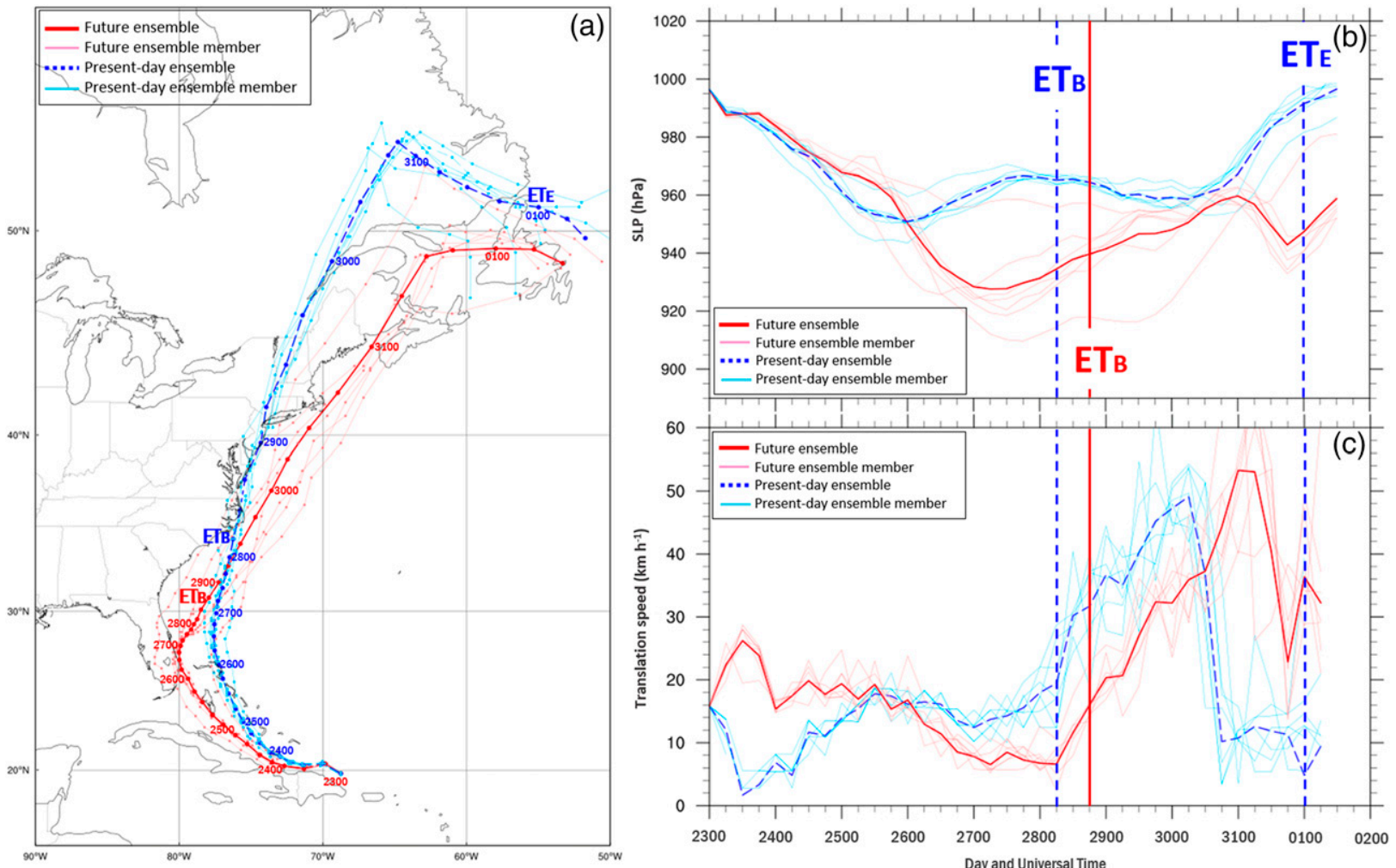

FIG. 7. As in Fig. 5, except for partially idealized experiments.

due to differences in track and land interaction between the present-day and future simulations. Unless explicitly stated, all analyses presented subsequently (both present day and future) are based on these partially idealized experiments. The future ensemble mean intensity of Irene is substantially greater than the present-day values, with a minimum SLP more than $20 \mathrm{hPa}$ lower than for the present-day ensemble mean at several points in the TC life cycle (Fig. 7b). As in the realistic orography experiments, there is again a poleward migration of the latitude of the storm maximum intensity evident in these simulations.

The onset and completion of ET for the seven-member ensemble mean are denoted $\mathrm{ET}_{B}$ and $\mathrm{ET}_{E}$ (Fig. 7); relative to the realistic orography simulations, the ET process takes longer and spans a greater range of latitude in these oceanic simulations. The completion of ET in the partially idealized future ensemble mean did not occur by the end of the model simulation, owing to the lingering presence of a warm core according to the CPS diagrams (Fig. 8). Comparison of Figs. 6 and 8 reveals that the partially idealized (oceanic) simulations exhibit stronger warm-core TC structures. The future simulations retain a warm core, measured by the lower-tropospheric thermal wind (i.e., $-V_{T}^{L}$ ), such that the ET process is not complete even at the end of the simulation (Fig. 8). For this reason, the end of the simulation is treated as the completion of ET in the partially idealized future ensemble mean. The slower northward translation speed in the future simulations, evident between 0000 UTC 26 August and 30 August, could also contribute to the extended duration of ET, although the onset of ET begins at a lower latitude in the future simulations (Fig. 7a).

The temporally averaged future ensemble minimum SLP is $\sim 17 \mathrm{hPa}$ deeper than that of the present-day ensemble during the ET period (Fig. 7b). Time series of storm-centered composite of 3-h precipitation rate superimposed on minimum SLP reveal that the enhanced precipitation rate is consistent with the lower minimum SLPs, especially during the early stages in the future composite, implying that diabatic heating drives greater intensification (Fig. 9). The intensified future ensemble mean Irene maintains a lower minimum SLP with corresponding strengthened wind speed until the end of simulation.

To provide additional information regarding nearsurface conditions, we examined changes in stormcentered 10-m wind speed during ET (Fig. 10). A TC undergoing ET often loses its axisymmetric appearance and exhibits an increasing radius of maximum wind 

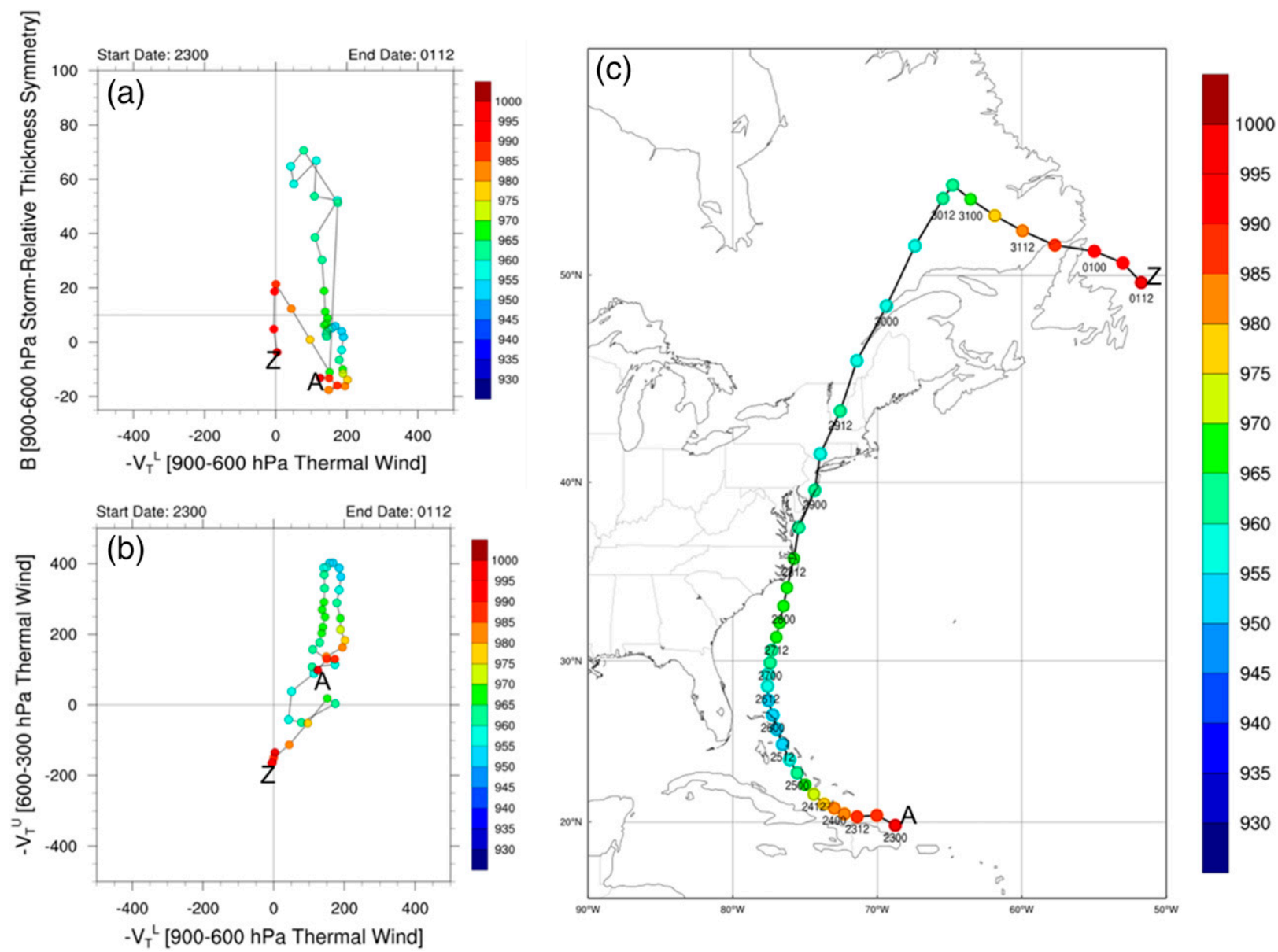

FIG. 8. As in Fig. 6, except for partially idealized simulations.

(Jones et al. 2003; Evans et al. 2017). Analysis of the storm-centered composite $10-\mathrm{m}$ wind speed superimposed on SLP for the future and present-day systems clearly indicates that the wind field becomes increasingly asymmetric and that the radius of maximum wind (RMW) expands during ET in both the future and present-day composites, consistent with prior studies (Fig. 10). The future composite indicates a more symmetric appearance and stronger wind field associated with a tightening of the SLP contours surrounding the center of the transitioning Irene at the initial stage of ET (Figs. 10b,e). This indicates that the future storm more strongly retains its tropical characteristics (e.g., symmetric appearance and warm core); this result is also consistent with the CPS diagrams (Fig. 8). As ET progresses, the leftof-center wind maximum lingers and expands only in the future composites and at the later stages of ET. The future storm thus retains its expanded gale-force wind for a longer period. We speculate that this wind maximum could be associated with the simulated reintensification period toward the end of the future simulation
(Fig. 7b); thus, this result may be case-dependent. Temporally and spatially averaged storm-centered composite $10-\mathrm{m}$ wind speeds are up to $6 \mathrm{~m} \mathrm{~s}^{-1}$ stronger for the future ensemble during ET (Fig. 10o).

On the basis of the analysis of time series of 3-h precipitation rate superimposed on minimum SLP presented in Fig. 9, we hypothesized that enhanced latent heat release results in an intensification of the future transitioning Irene. To further investigate this, we present $900-750-\mathrm{hPa}$ layer average potential vorticity (PV) fields (Fig. 11); numerous previous studies have established the utility of PV to understand TC dynamics (e.g., Möller and Montgomery 2000; Wang 2002; Hill and Lackmann 2011). The present-day and future 900-750$\mathrm{hPa}$ layer average PV reveals a more intense PV maximum in the future ensemble mean during ET, consistent with increased precipitation and diabatic PV generation, especially within the core of the transitioning Irene (Fig. 11c); this finding is consistent with previous studies of TC intensity change with warming (e.g., Hill and Lackmann 2011). The PV difference field also shows 

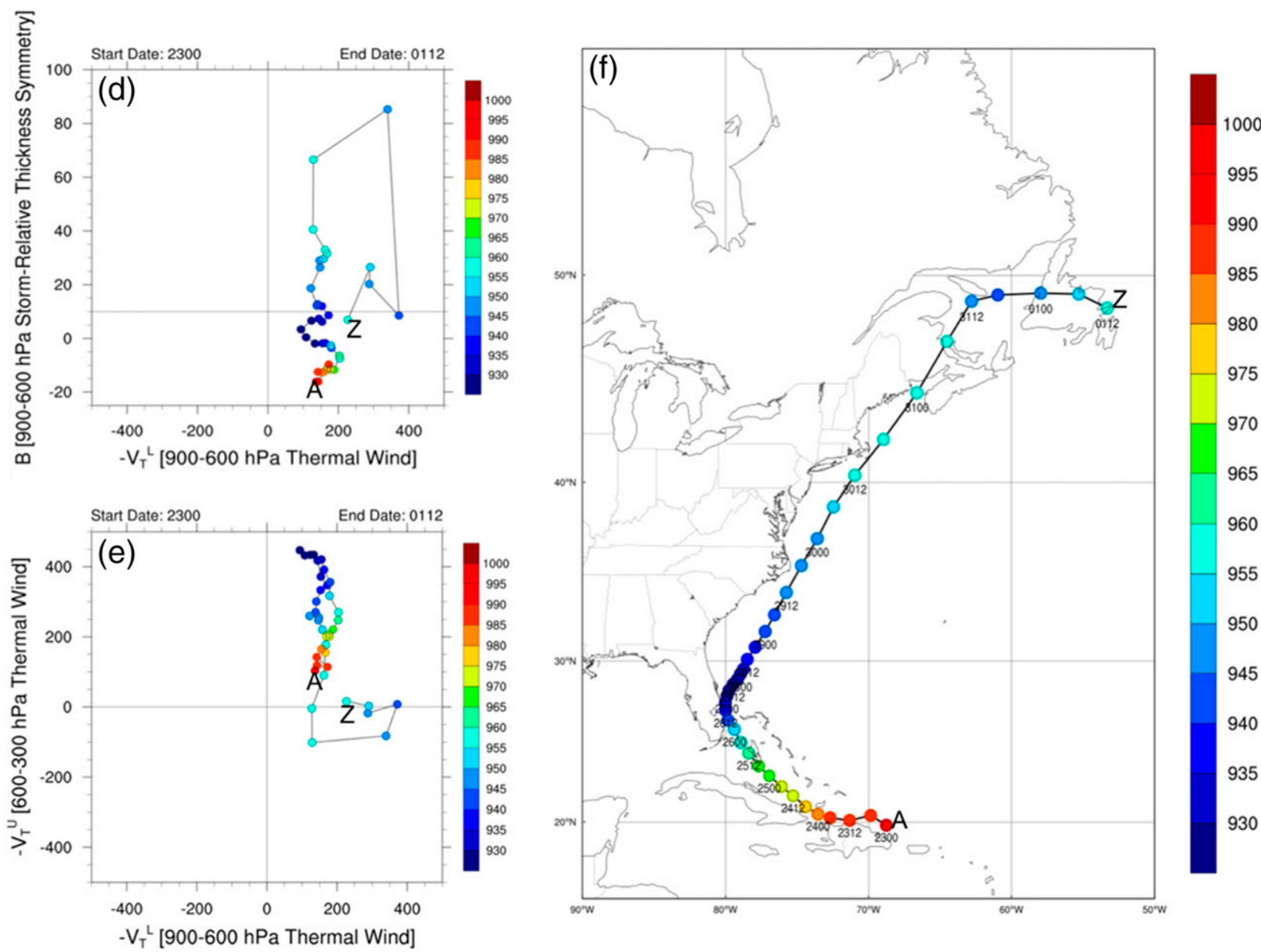

FIG. 8. (Continued)

positive changes at larger radial distances from the storm center, consistent with the expanded wind field shown in Fig. 10. These findings indicate a somewhat larger storm size in the future, perhaps due to mechanisms such as those discussed by Hill and Lackmann (2009b).

Although the role of increased diabatic heating is found to be important to strengthened intensity during the ET of future Irene, the importance of changes in environmental baroclinicity to intensity changes is also worthy of consideration. It is possible that the future increases in intensity during ET found here are largely due to an environment with a greater potential for baroclinic growth. To assess the role of environmental baroclinicity for the future strengthening of transitioning Irene, we computed the 850-500-hPa maximum Eady growth rate, given by

$$
\sigma_{E_{-} \max }=0.31 \frac{f_{0}}{N} \frac{\partial U_{0}}{\partial z},
$$

where $f_{0}$ is the Coriolis parameter at some reference latitude, $N$ is the Brunt-Väisälä frequency, and $\partial U_{0} / \partial z$ is the base-state (temporally averaged) vertical wind shear [Lindzen and Farrell 1980, their (28)]. The temporally and spatially averaged, storm-centered composite maximum Eady growth rate reveals that baroclinicity is only slightly increased $(\sim 4 \%)$ for the future ensemble during the temporally averaged ET period (Fig. 12c). This suggests that changes in baroclinicity are not likely to dominate diabatic changes in the intensification of the simulated future ET event. It is worth noting that even though the averaged composite maximum Eady growth rate during the entire ET process is slightly increased, the average rate from ET onset to the mid-stage of ET is considerably increased $(\sim 13 \%)$ in the future ensemble (Figs. 8a,d), meaning the future weakened baroclinicity during the early- and mid-stage of ET would be favorable to maintaining the storm's tropical aspect. Another difference between the present-day and future simulation is that nearly all future ensemble simulations exhibited a $\sim 15-\mathrm{hPa}$ decrease in minimum SLP during the period from 0000 to 1800 UTC 31 August; the present-day ensemble mean storm is filling during this 


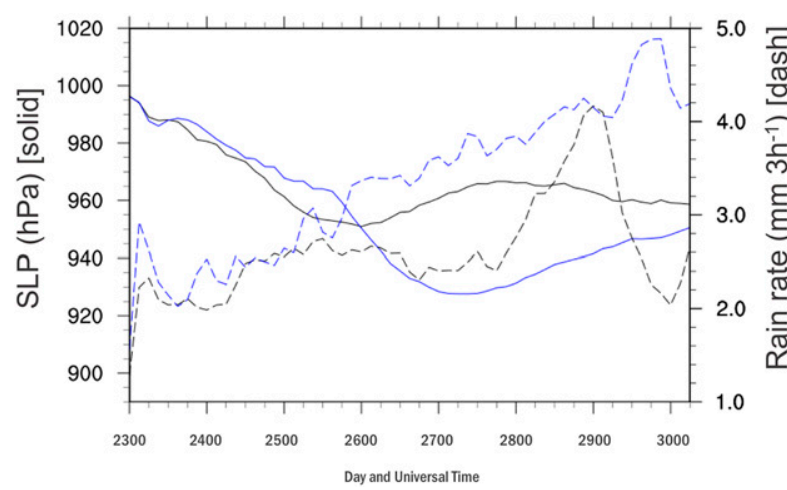

FIG. 9. Time series of spatially averaged storm-centered composites of future ensemble 3 -h precipitation rate $\left[\mathrm{mm}(3 \mathrm{~h})^{-1}\right.$; dashed lines] and minimum sea level pressure (hPa; solid lines) for the realistic orography experiments (black lines) and partially idealized experiments (blue lines) during the ET period.

time (Fig. 7b). Computations of spatially averaged storm-centered ensemble mean Eady growth rate reveals an increase in baroclinicity during this period in the future simulations (Table 4), implying the future rapid increase in intensity found at the end of the simulation is largely due to an environment with a greater baroclinic potential for growth. Examination of 500-hPa geopotential heights and SLP reveals excellent phasing between Irene and a midlevel trough in the future simulations (Figs. 13b,d), consistent with many previous ET studies (e.g., DiMego and Bosart 1982; Sinclair 1993; Bosart and Lackmann 1995; Klein et al. 2002; Ritchie and Elsberry 2003). There is a secondary trough axis to the west of the TC in the future simulations, which aids this favorable configuration (Fig. 13b). The upper trough in the present-day simulations do not show this secondary feature (Figs. 13a,c). Additionally, ridge amplification and jet stream intensification occur as the storm moves poleward due to the tropospheric outflow associated with the storm interacting with the jet stream (e.g., DiMego and Bosart 1982; Klein et al. 2000; Sinclair 2002; Agusti-Panareda et al. 2004; Archambault et al. 2013, 2015). The upper-level jet maximum is located immediately to the east of the surface storm during the period of deepening in the future ensemble (not shown). These results demonstrate that while the environmental baroclinicity is not the primary factor responsible for the greater intensity of the future Irene over the entire ET process, it plays a significant role in rapid reintensification at the end of the future simulation. The details of phase interactions such as those shown here may be highly case-dependent, while changes in diabatic process are likely to be of more general relevance in warming environments.

\section{b. Precipitation}

In the realistic orography simulations, the stormcentered composite 3-h precipitation rate during ET reveals that the present-day Irene produces less precipitation than its future counterpart, consistent with expectations and with previous studies (Fig. 14). Except for a limited northern outer semicircle of the storm, the
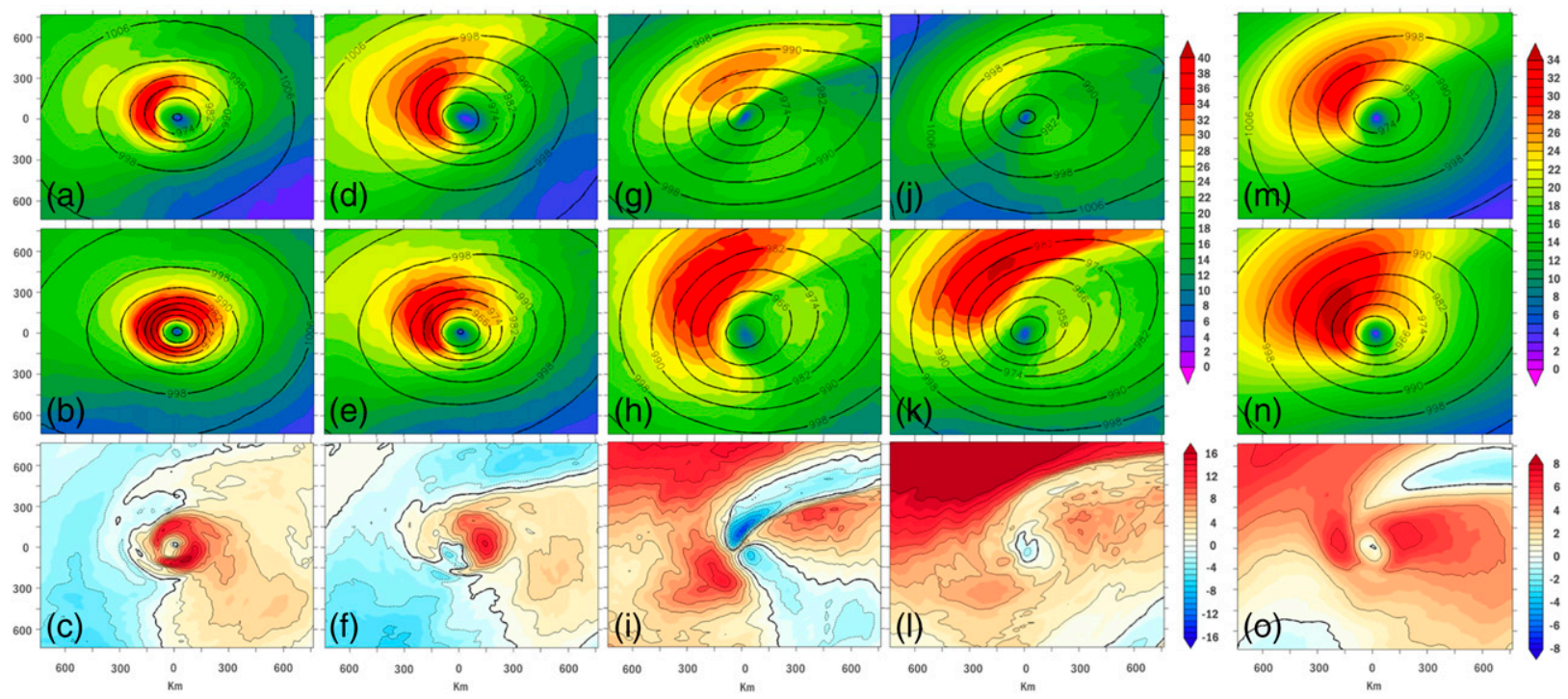

FIG. 10. Comparison of present-day and future storm-centered composite of $10-\mathrm{m}$ wind speed (shaded as in legend; $\mathrm{m} \mathrm{s}^{-1}$ ) and sea level pressure (contoured; 8-hPa interval) at (a),(b) the onset of ET, (d),(e) $\mathrm{ET}_{B}+24 \mathrm{~h},(\mathrm{~g}),(\mathrm{h}) \mathrm{ET}_{B}+60 \mathrm{~h}$, and (j), (k) $\mathrm{ET}_{B}+72 \mathrm{~h}$ in a partially idealized environment. (c),(f),(i),(l) Future differences in 10-m wind speed (shaded and contoured) during the ET period. (m)-(o) As in (a)-(1), but for temporally averaged storm-centered composite of 10-m wind speed and sea level pressure during the ET period. The 10-m wind speed is computed after subtraction of storm translation speed. 

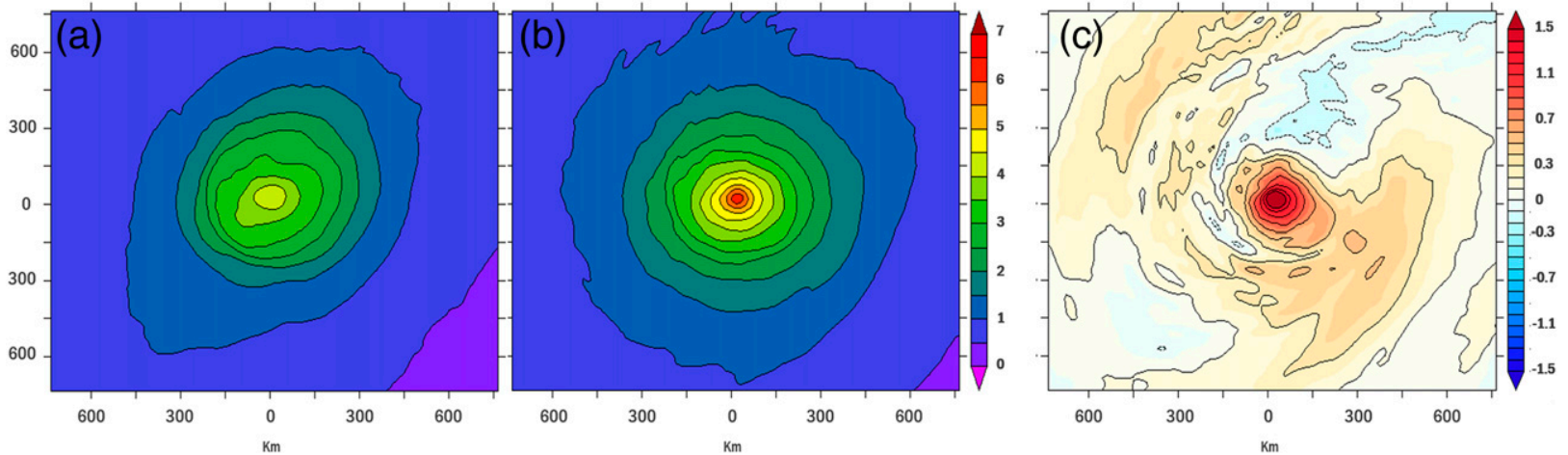

FIG. 11. Temporally averaged storm-centered composite of 900-750-hPa layer average PV (PVU; $1 \mathrm{PVU}=10^{-6} \mathrm{~K} \mathrm{~kg}^{-1} \mathrm{~m}^{2} \mathrm{~s}^{-1}$ contour/ fill) for (a) present day, (b) future, and (c) future difference in the layer average PV (future minus present) during the ET period. Results are for the partially idealized simulations.

future change in the composite clearly shows an increase in the 3-h precipitation rate in the vicinity of the TC (Fig. 14c); the spatially averaged value during ET yields an increase of $\sim 2 \%$. Given an approximate $4.7-\mathrm{K}$ increase in the corresponding average storm-centered $850-\mathrm{hPa}$ temperature, the atmospheric water vapor is expected to increase to $\sim 30 \%$ in accordance with the Clausius-Clapeyron relation. The increase in the stormcentered composite precipitation is thus far below the Clausius-Clapeyron-driven water vapor increase during ET in the future simulations. However, these projected changes in precipitation may be due to changes in temperature near Irene resulting from shifts in its track, or to changes in orographic lift due to track changes. The area of decreased precipitation to the north of Irene is likely related to the eastward track shift for the future Irene. Orographic enhancement of precipitation is stronger in the present-day simulations considering the present-day storm's track crossing complex terrain near New England, and the eastward future track shift appears to lead to a less favorable flow orientation relative to the mountainous terrain across New York and New England, resulting in substantial reduction of precipitation there (not shown). Thus, we
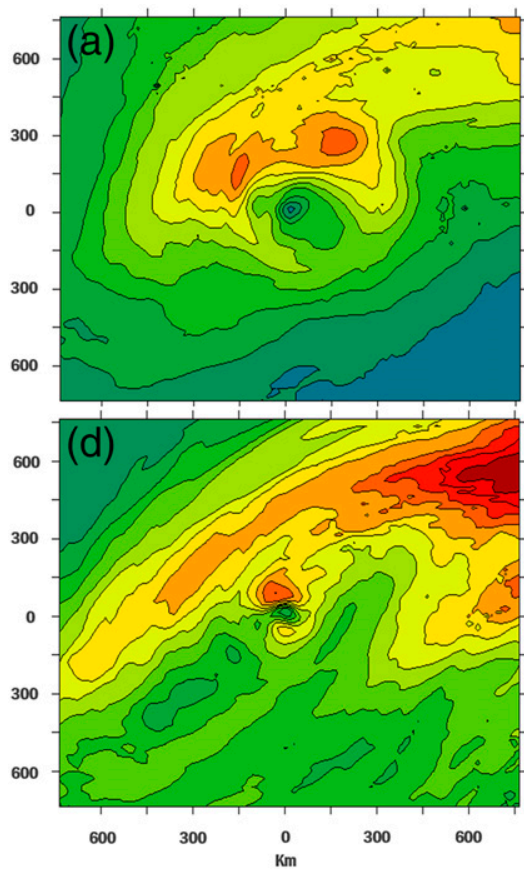
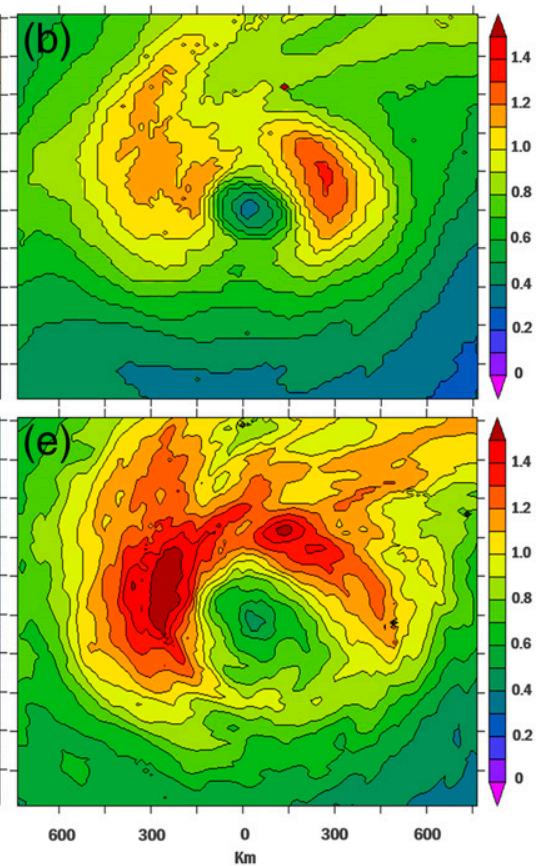
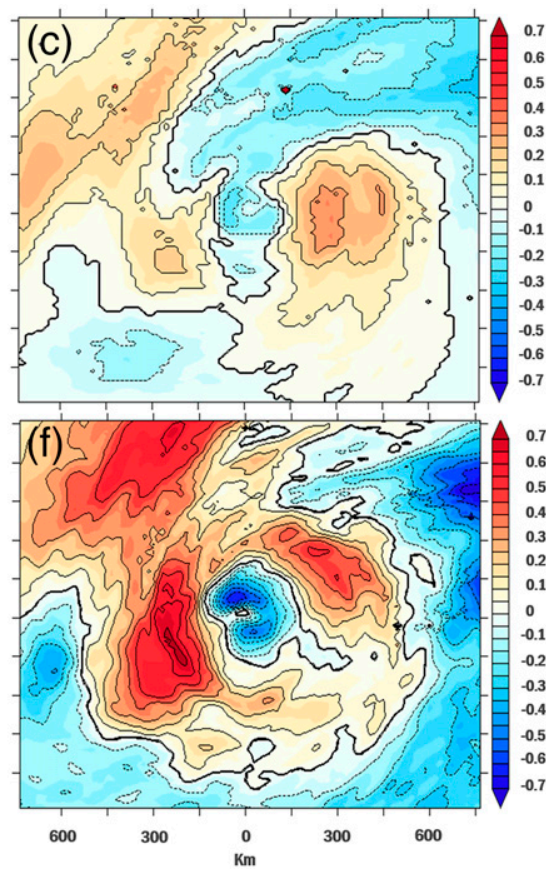

FIG. 12. Temporally averaged storm-centered composite of Eady growth rate maximum (contours and shading; day ${ }^{-1}$ ) for (a) present day, (b) future, and (c) difference in partially idealized environment during the ET period (future minus present); (d)-(f) as in (a)-(c), but during the rapid deepening period from 0000 to 1800 UTC 31 Aug 2011. 
TABLE 4. Maximum Eady growth rate mean for spatially averaged storm-centered composite data under partially idealized environment.

\begin{tabular}{lcc}
\hline $\begin{array}{c}\text { Period } \\
\text { experiment }\end{array}$ & $\begin{array}{c}\text { Extratropical } \\
\text { transition } \\
\left(\text { day }^{-1}\right)\end{array}$ & $\begin{array}{c}\text { Rapid reintensifying period } \\
\left.\text { for future ensemble (day }{ }^{-1}\right) \\
(\text { (0000 UTC-1800 UTC 31 Aug) }\end{array}$ \\
\hline Future & 0.715 & 0.896 \\
Present-day & 0.685 & 0.841 \\
Difference & 0.030 & 0.055 \\
\hline
\end{tabular}

must again utilize the partially idealized simulations in order to investigate future changes in precipitation without the influence of variations in land interaction and terrain.

As with the wind field, it is also useful to examine structural changes in precipitation during the ET period (Fig. 15). As Irene moves into a baroclinic environment, an asymmetric precipitation distribution associated with a widespread decrease of deep convection on the western side of the TC outer circulation develops in both the future and present-day storm. The region of heavy precipitation is mainly concentrated to the left of center and is more evenly distributed at the early stages of ET. Redistribution of the main precipitation region to the poleward side of the storm takes place with time in both the future and present-day experiments, consistent with prior studies (Atallah and Bosart 2003; Atallah et al. 2007; Liu and Smith 2016). The future storm has a clear axisymmetric (i.e., more TC-like) structure in the precipitation distribution relative to the present-day system at the early stages of ET, and the lingering presence of a warm core is also evident over the entire ET period as discussed previously (Figs. 15b,e,h,k).

In contrast to the full orography experiments, the temporally and spatially averaged, storm-centered
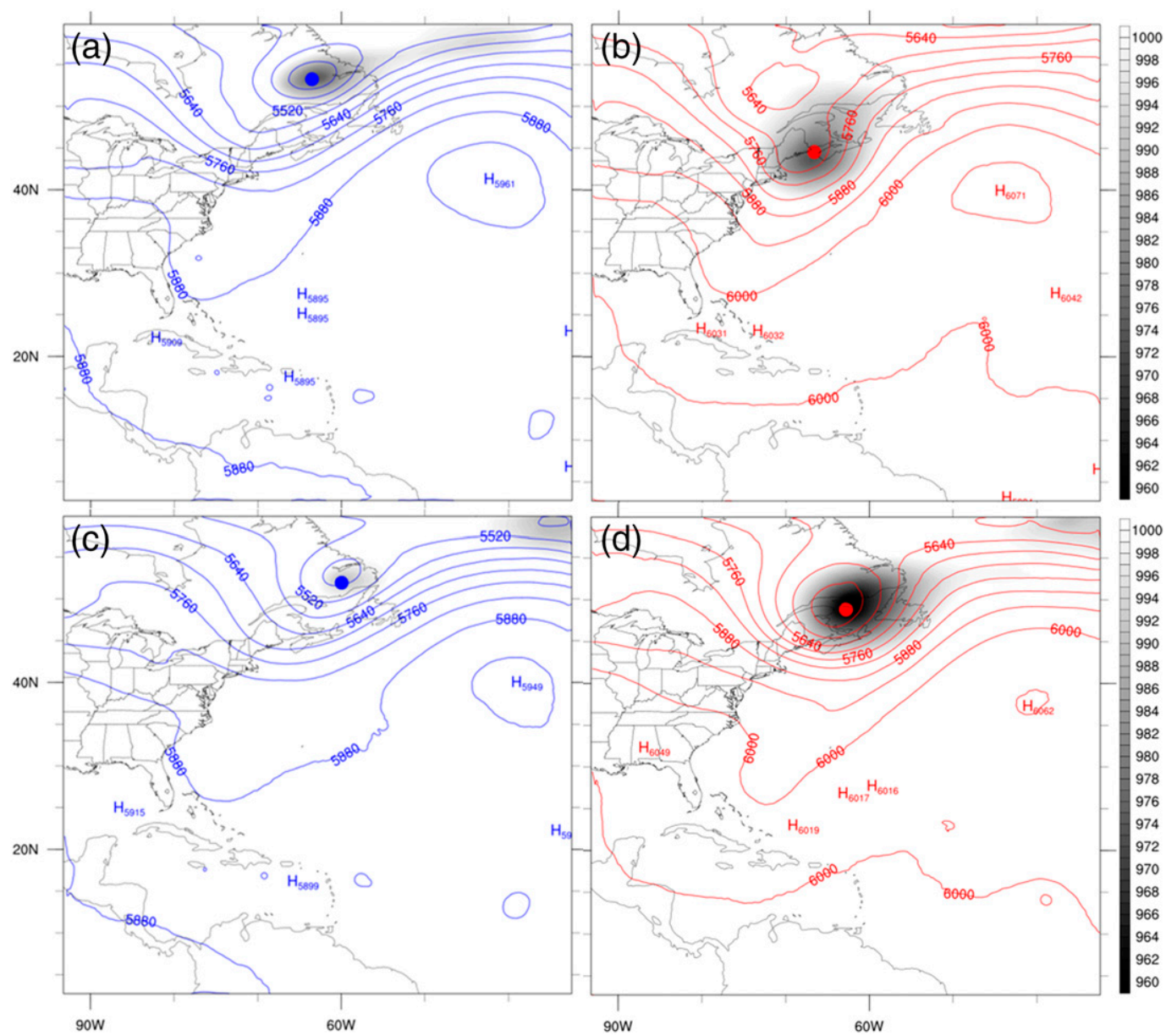

FIG. 13. The 500-hPa geopotential heights (contours; 60 -m interval) and sea level pressure (shaded; 2 -hPa interval for values $\leq 1000 \mathrm{hPa}$ ) at (a) 0000 UTC 31 Aug and (c) 1200 UTC 31 Aug for the partially idealized presentday ensemble. (b),(d) The corresponding fields for the partially idealized future ensemble. The location of the surface minimum pressure center is indicated with a red or blue dot. 

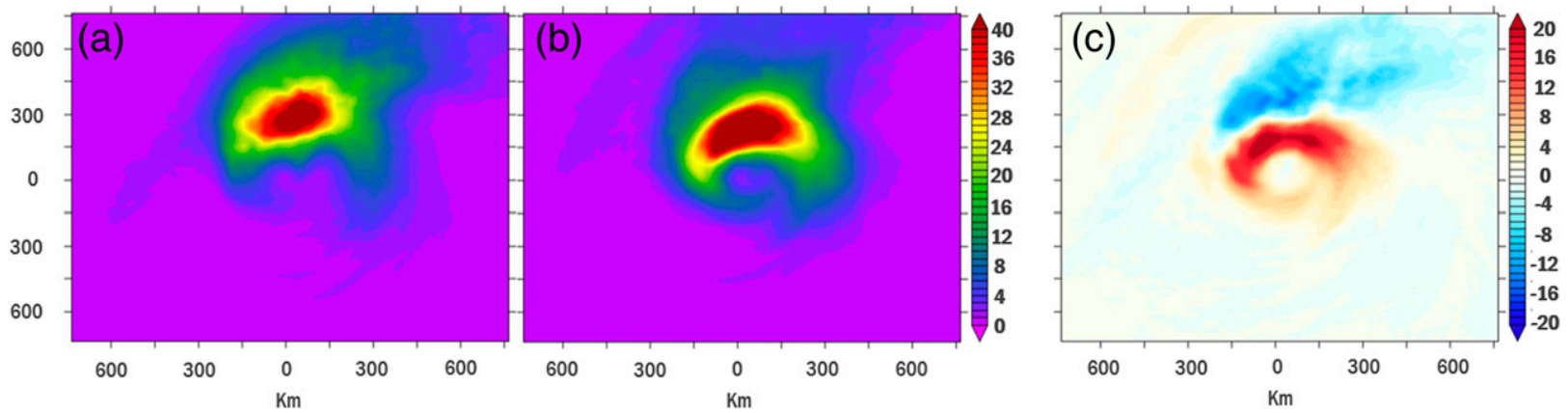

FIG. 14. Temporally averaged storm-centered composite of $3-\mathrm{h}$ precipitation rate $\left[\mathrm{mm}(3 \mathrm{~h})^{-1}\right]$ in (a) present day and (b) future with the realistic orography during ET period; (c) as in (a), but for future difference.

analysis of these partially idealized simulations exhibits a $\sim 68 \%$ increase in 3 -h precipitation rate, which is equivalent to an approximate $1.7 \mathrm{~mm}(3 \mathrm{~h})^{-1}$ increase (Fig. 15o). Additionally, there is an approximate 8.2-K increase in $850-\mathrm{hPa}$ temperature during the future ET period in these simulations, which means the stormcentered spatially averaged temperature in the partially idealized future simulations is much warmer compared to the realistic orography one. This is because the more intense storm in the partially idealized future simulations maintained its warm core to higher latitudes compared with the present-day storm. In addition, the storm in the partially idealized future simulations propagates slower after the recurvature point than the realistic orography one, which indicates the storm in the realistic orography simulations is located at a higher latitude than its counterpart at same time, implying it is exposed to relatively colder environment. The Clausius-
Clapeyron relation suggests an atmospheric water vapor increase of $\sim 6.5 \%$ for every degree of warming, so the increase of $8.2 \mathrm{~K}$ in temperature corresponds to a $\sim 52 \%$ increase in atmospheric water vapor content. The computed water vapor change between future and current in the partially idealized ensemble mean demonstrates an increase of $\sim 63 \%$ in terms of specific humidity at $850 \mathrm{hPa}$. This means that the projected spatially averaged storm-centered composite precipitation rate exceeds the vapor increase indicated by the ClausiusClapeyron relation.

Before exploring the cause of increase in future precipitation, it is worth discussing how anthropogenic forcing gives rise to changes in TC precipitation. First, even with the same storm circulation, increases in specific humidity with warming would yield greater moisture-flux convergence and precipitation. Second, a stronger storm features a stronger secondary circulation
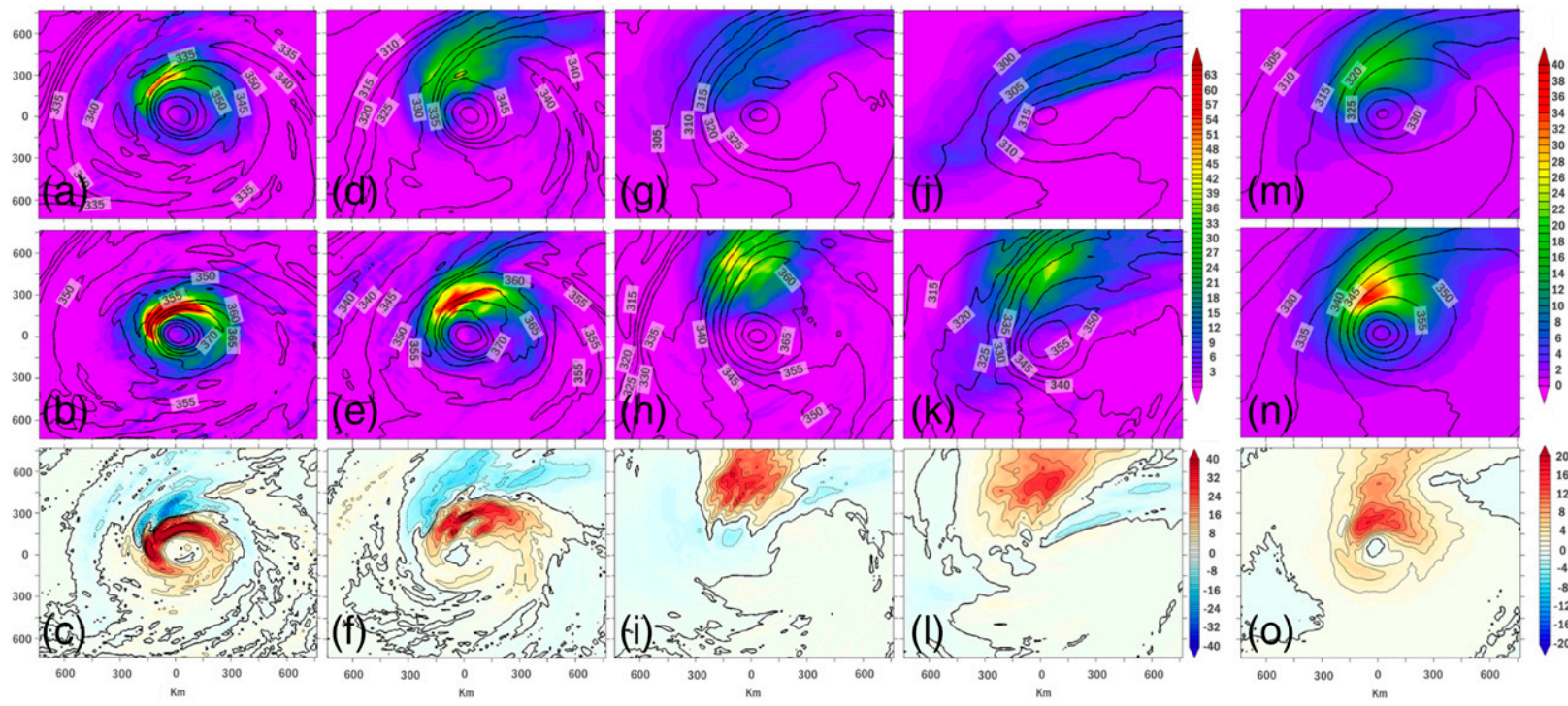

FIG. 15. As in Fig. 10, but for storm-centered composite of 3 -h precipitation rate [shaded; $1 \mathrm{~mm}(3 \mathrm{~h})^{-1}$ interval] and equivalent potential temperature (contour; 5-K interval). Results are for partially idealized simulations. 
TABLE 5. Mean and standard deviation (the numbers following the \pm sign) for spatially averaged storm-centered composite data under partially idealized environment during ET. Column integration was taken for evaporation and moisture flux between $1000 \mathrm{and} 300 \mathrm{hPa}$, and for mass convergence between 1000 and $700 \mathrm{hPa}$.

\begin{tabular}{lccccc}
\hline \hline Experiment & $\begin{array}{c}\text { Precipitation } \\
{\left[\mathrm{mm}(3 \mathrm{~h})^{-1}\right]}\end{array}$ & $\begin{array}{c}\text { Evaporation + moisture } \\
\text { convergence }\left[\mathrm{mm}(3 \mathrm{~h})^{-1}\right]\end{array}$ & $\begin{array}{c}\text { Evaporation } \\
{\left[\mathrm{mm}(3 \mathrm{~h})^{-1}\right]}\end{array}$ & $\begin{array}{c}\text { Moisture convergence } \\
{\left[\mathrm{mm}(3 \mathrm{~h})^{-1}\right]}\end{array}$ & $\begin{array}{c}\text { Mass convergence } \\
\left(\mathrm{kg} \mathrm{m}^{-2} \mathrm{~s}^{-1}\right)\end{array}$ \\
\hline Future & $4.14 \pm 0.38$ & $4.25 \pm 0.43$ & $0.96 \pm 0.15$ & $3.29 \pm 0.28$ & $0.0495 \pm 0.0021$ \\
Present-day & $2.46 \pm 0.24$ & $2.25 \pm 0.25$ & $0.55 \pm 0.05$ & $1.70 \pm 0.20$ & $0.0431 \pm 0.0031$ \\
Difference & 1.68 & 2.00 & 0.41 & 1.59 & 0.0064 \\
\hline
\end{tabular}

and greater mass and moisture convergence. Third, stronger wind speeds in a strengthened storm increase the surface latent heat flux. These effects each contribute to greater precipitation with warming. To determine which of these processes is dominant in our simulations, we follow the methods of Trenberth et al. (2007) and compute an approximate water budget, focusing on the three key components: surface moisture flux, convergence of atmospheric moisture into the storm, and precipitation.

Analysis of the spatially averaged storm-centered composite moisture flux convergence and surface evaporation rate during ET confirms that the increase in the ocean source of vapor is relatively small relative to convergence of moisture flux, with the ocean vapor source being approximately $26 \%$ of the increase in moisture flux convergence (Table 5). There is also an increase of $\sim 15 \%$ in the overall mass convergence into the storm, which also contributes to the increased overall moisture flux convergence. These results are in agreement with earlier modeling studies (e.g., Braun 2006; Trenberth et al. 2007) and the processes discussed previously, and suggest that the moisture budget in the future ET of Irene is dominated by moisture flux convergence with an additional contribution from surface evaporation. Since various other feedbacks also are at work and other processes, such as atmospheric stability changes, frictional effects, and cold wake effects on SST are known to be important for the precipitation in storms, the net values of computed moisture flux convergence, precipitation, and surface evaporation are subject to considerable uncertainty (Table 5).

\section{c. The length of the ET period}

While the length of time taken for the present-day ensemble mean of Irene to complete ET is approximately $30 \mathrm{~h}$, completion of ET in the future ensemble mean Irene takes $18 \mathrm{~h}$ longer in the realistic orography experiments. As discussed previously, in the partially idealized experiments, ET is not complete even at the end of the simulations for the future Irene in all seven ensemble members, which implies an extended ET period in these future simulations (Fig. 7). To see the distinct environments of the present-day and future transitioning Irene, future changes in SST and vertical wind shear in the realistic orography experiments are also examined in addition to examination of changes in the partially idealized experiments because the completion of ET was not evident in the future partially idealized experiments.

According to Hart et al. (2006), rapidly transitioning TCs are often associated with high-amplitude troughs over cool SST, enabling the TCs to translate meridionally across the Atlantic rather than zonally, leading to ET acceleration. A substantial difference in midlevel trough amplitude does not exist between our presentday and future simulations owing to our experimental design. However, an analysis of changes in the midlevel trough reveal that the amplitude of the 500-hPa trough slightly decreases in the both the realistic orography and partially idealized future ensembles prior to ET (Fig. 16). In other words, present-day Irene is associated with a relatively higher-amplitude trough relative to the future one during the early stages of ET. In addition, the greater amplification of the ridge downstream of Irene is evident in the future simulations as well as discussed in section 4a (Fig. 16). This is because the imposed thermodynamic changes can also lead to dynamical changes as well during the event, as described in section $2 \mathrm{~b}$. To quantify the geopotential height rise downstream of Irene, we compute 500-hPa geopotential height anomalies as departures from an ET time average (corrected for domain-average height increases in the future simulations). The future downstream ridge is significantly amplified in both sets of simulations (Fig. 16), consistent with prior studies (e.g., Harr and Dea 2009; Keller et al. 2014; Quinting and Jones 2016; Keller 2017; Keller et al. 2019). The greater downstream ridge amplification is consistent with increased future precipitation rates as discussed in section 3a (Fig. 9). This finding could have important implications for downstream development of Rossby wave trains and perhaps even predictability (e.g., Grams et al. 2013b; Aiyyer 2015). With increased ridging in conjunction with a lower-amplitude upstream trough, the future Irene is advected somewhat more 

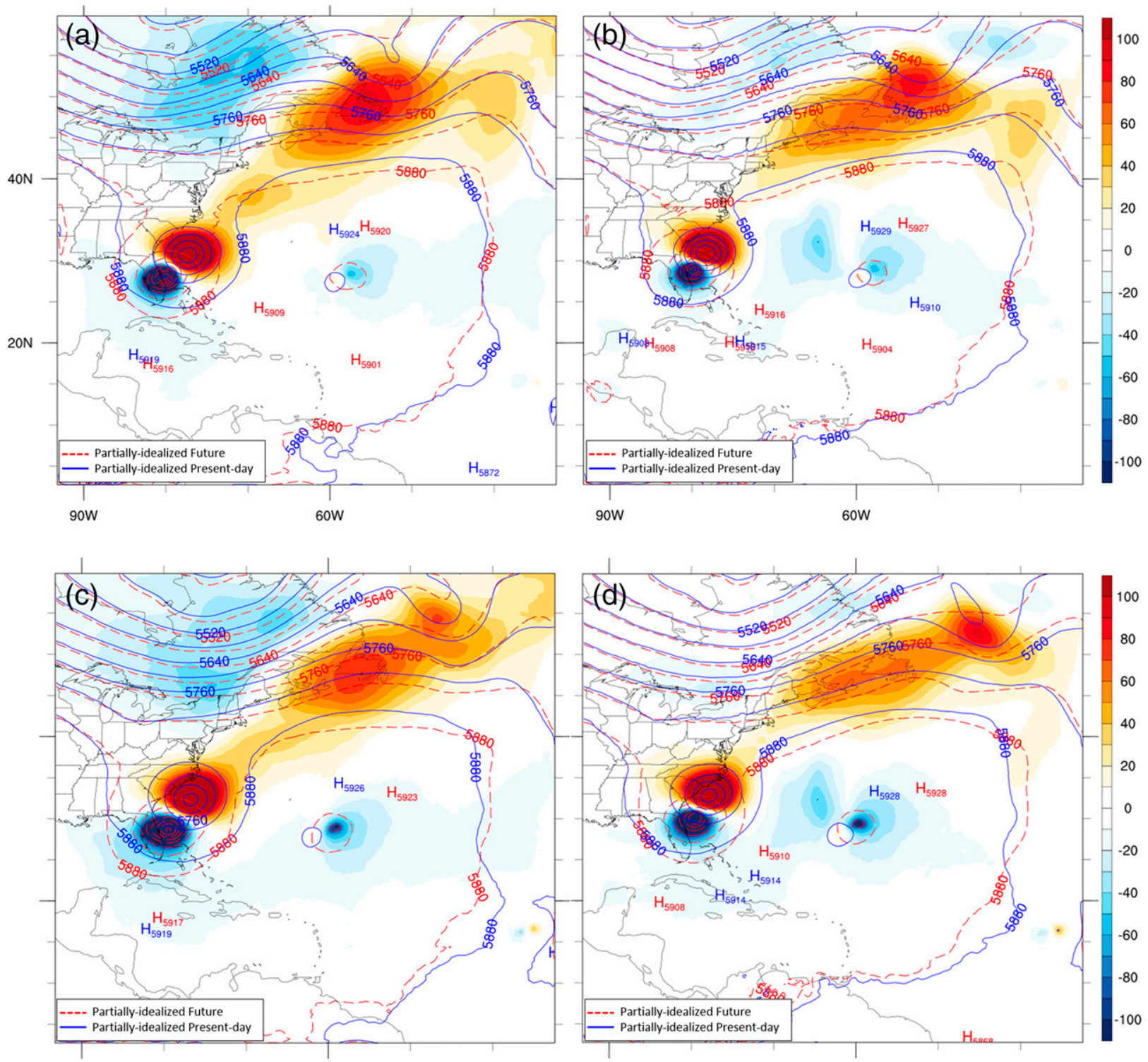

FIG. 16. The 500-hPa geopotential height for future ensemble (red dashed contours; 60-m interval), present-day ensemble (blue solid contours; $60-\mathrm{m}$ interval), and 500-hPa geopotential height anomaly difference between future and present-day ensemble (shading; $10-\mathrm{m}$ interval) in the (a) partially idealized and (b) realistic environments at 0600 UTC 27 Aug; (c),(d) as in (a) and (b), but at 1800 UTC 27 Aug. The 500-hPa geopotential heights in the future ensemble are normalized by subtracting the height difference between future and present day at the initial time. The anomalies are calculated by subtracting an average height from $\mathrm{ET}_{B}-24 \mathrm{~h}$ to end of simulation.

zonally relative to the present-day Irene, prolonging the ET process. In addition, a significant reduction in the meridional SST gradient in the future environment is seen, which may also contribute to slowing the ET process in the future Irene (Figs. 17a,b) relative to the present-day system. This feature is also found in the CPS diagrams (Figs. 6, 8), indicating the future ensemble storm has generally small $B$ values over the entire ET process, implying it is likely to maintain its axisymmetric structure to higher latitudes. The smaller $B$ values, in turn, represent a weaker baroclinicity, which imply the future storm would progress under a weaker baroclinic environment relative to the present-day system, consistent with our findings above. Temporally averaged 300$850-\mathrm{hPa}$ vertical wind shear magnitude during the whole integration time is weaker over most of the track of the storm (Figs. 17c,d). Given that a smaller and weaker (i.e., present-day Irene) storm would be more prone to the shearing effects of a midlatitude trough (e.g., Hart et al. 2006), a larger and stronger (i.e., future Irene) 

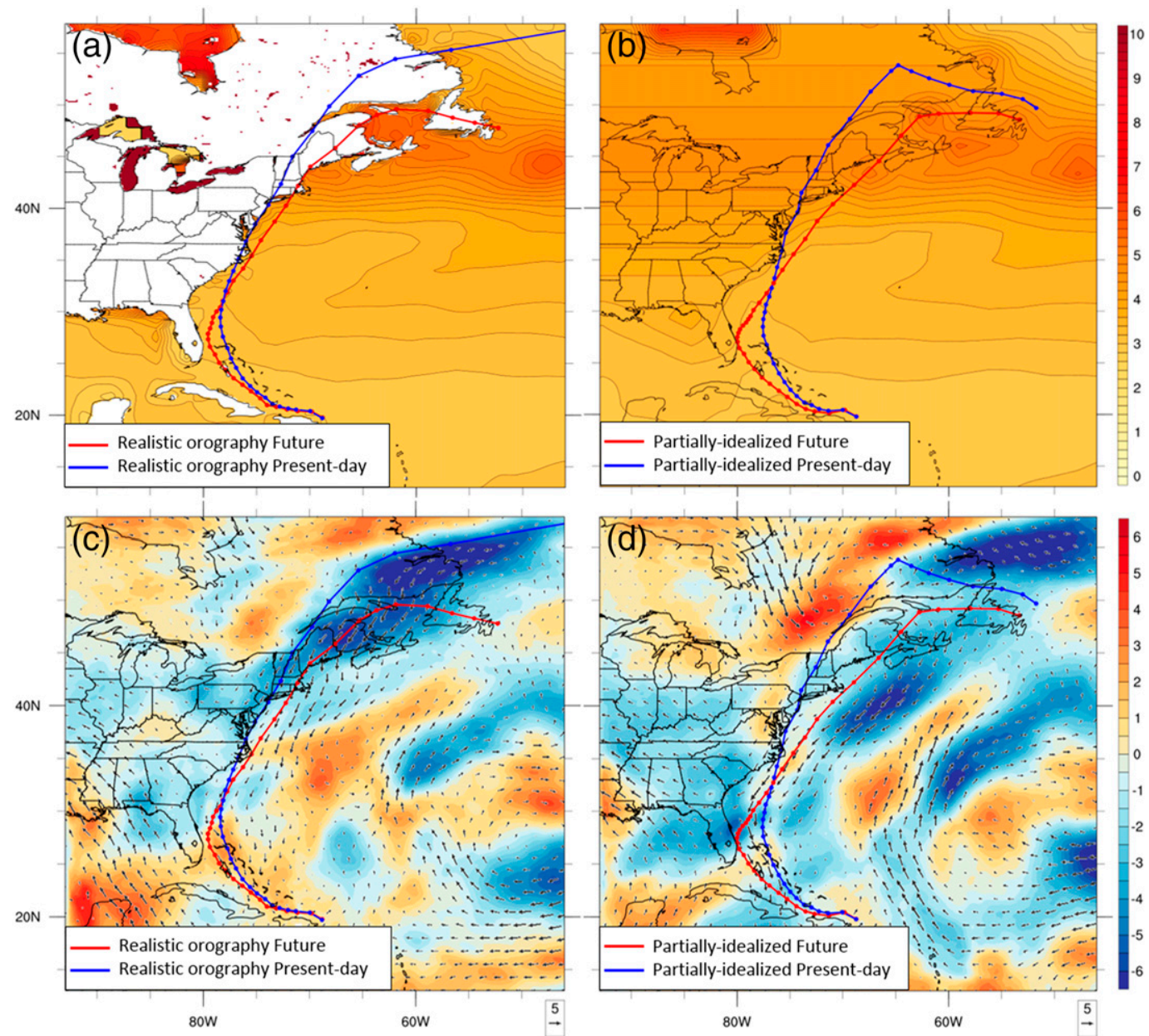

FIG. 17. Temporally averaged Earth-relative (a),(b) sea surface temperature (K) difference between future and present day, and (c),(d) 300-850-hPa vertical wind shear magnitude (shaded; $\mathrm{m} \mathrm{s}^{-1}$ ) and vector ( $\mathrm{m} \mathrm{s}^{-1}$ ) in (left) realistic orography and (right) a partially idealized environment superimposed on ensemble tracks (red solid lines, future; blue solid lines, present day) during entire simulation period. The onset and completion of ensemble ET are labeled $\mathrm{ET}_{B}$ for the onset and $\mathrm{ET}_{E}$ for the completion of transition.

storm in a weakened wind shear environment is likely to more slowly lose its tropical aspects. As discussed in section $3 \mathrm{a}$, given that the future storm generally propagated more slowly northward than the present-day system, it is reasonable to ask if future ET lasts longer because of delayed interactions with jet stream features. The ET time-averaged translation speed of the future storm is faster than its counterpart (i.e., $\sim 33 \mathrm{~km} \mathrm{~h}^{-1}$ for the future storm, $\sim 27 \mathrm{~km} \mathrm{~h}^{-1}$ for the present-day system) in the partially idealized ensemble; even though the future storm slowly propagated northward until the initial stage of ET, it progressed faster than the presentday system during the middle stages (Fig. 7c). The same computation for the realistic orography storm depicts slightly reduced future speed (i.e., $\sim 30 \mathrm{~km} \mathrm{~h}^{-1}$ for the future storm, $\sim 34 \mathrm{~km} \mathrm{~h}^{-1}$ for the present-day system).
The slower future northward progression and a track closer to the east coast of Florida during the recurving period contribute to the delayed onset of ET. However, this takes place at a lower latitude compared with the present-day location of ET onset because of the slower movement, due to the corresponding delay of TCtrough interaction in the future (Fig. 5a), as previously discussed. The reduction in meridional SST gradient in the future both in the realistic orography and partially idealized experiments implies that reduced future baroclinicity also contributes to the extended duration of ET as well. Computations of temporally averaged 850 $500-\mathrm{hPa}$ Eady growth rate in the realistic orography ensemble during prior to ET shows a $\sim 7 \%$ decrease in the future (not shown). The delayed onset of ET in the future simulations appears to be attributable both to 
delayed TC-trough interaction caused by the slower northward translation and to the decreased baroclinicity at low latitudes. Additionally, the future storm completes ET at a higher latitude despite a slower speed, implying that other factors, including future TC-favorable environments aside from the translation speed difference, also contribute to increases in the duration of ET in the future simulations.

\section{Discussion and conclusions}

Changes in the intensity or structure of transitioning TCs with climate warming are highly relevant to society. This study presents an initial investigation of such possible changes based on numerical simulations of Hurricane Irene (2011), which was a strong ET event. We utilize a small ensemble and two sets of experiments to investigate changes in intensity, rainfall rate, and ET duration. These experiments are based upon change fields computed from 20 CMIP5 RCP8.5 GCM projections. Initial experiments with realistic orography exhibited differences in land interaction, complicating interpretation of results and making it difficult to isolate storm differences due to the larger-scale thermodynamic changes. Therefore, we developed a second set of partially idealized experiments with entirely oceanic domains.

We hypothesized that transitioning TCs may exhibit greater strengthening with warming relative to TCs remaining in tropical environments. This is based on previous findings that document the mitigating influence of the projected tropical upper-tropospheric warming maximum (e.g., Shen et al. 2000; Hill and Lackmann 2011). Recurving or transitioning TCs may become spatially separated from this mitigating feature. The results of the partially idealized experiments demonstrate that large-scale thermodynamic change influences the intensity, precipitation pattern, strength, and duration of ET process of Hurricane Irene, despite a highly similar current and future synoptic weather patterns. Key findings from the partially idealized experiments include the following:

- The ensemble mean precipitation rate increase exceeded the water vapor increase described by the Clausius-Clapeyron relation.

- The duration of the ET process extended substantially with warming.

- Downstream ridging was stronger in future simulations, consistent with heavier precipitation and stronger latent heat release.

- The ensemble mean intensity in future simulations was substantially stronger, exhibiting greater relative intensification than seen in many previous TC studies.
The mechanisms responsible for increased future intensity in this case are more clearly related to increases in diabatic processes than changes in baroclinicity. Given the enhanced latent heat release during ET, we expect to see heavier precipitation in the future transitioning Irene. Storm-centered composites of 3-h precipitation rate in the partially idealized experiments during ET indeed reveal increases in precipitation rate that exceed Clausius-Clapeyron scaling. A bulk waterbudget analysis indicates that this is attributable to an increase in moisture flux convergence in addition to a surface evaporation increase. Here, results from the realistic orography simulations differed; the future 3-h precipitation rate increase in those simulations was far below the Clausius-Clapeyron-driven water vapor increase during ET, likely due to differing orographic lift due to the change of the TC track; this is consistent with the study of Liu and Smith (2016).

The duration of ET in the future Irene is $18 \mathrm{~h}$ longer than that of the present-day one in the realistic orography experiments, and the completion of ET fails to occur by the end of the future simulations in the partially idealized experiments. These results consistently imply that the ET process may be prolonged in warmer climates, suggesting that ET events in a warmer environment could bring TC-like conditions even farther poleward than at present, especially in the Atlantic where GCM-derived SST changes maximize warming north of the Gulf Stream. With the reduction of the meridional SST gradient, weakening in vertical wind shear is evident along the track of the storm in the future ensemble, meaning that the future environmental conditions would be more favorable for maintenance of tropical characteristics during the ET process, a result consistent with the work of Liu et al. (2017). In addition, slower northward translation speeds in the future simulations could also contribute to the extension of ET duration. Examination of additional cases will be required to test the generality of these results. More pronounced downstream ridging in future simulations also holds interesting implications regarding downstream development and predictability (e.g., Keller et al. 2019, their section 5, final paragraph). As described previously, one of our initial hypotheses was that TCs moving out of the tropics would exhibit a larger increase in intensity with warming relative to those remaining in the tropics owing to changes in near-storm atmospheric stability: Poleward moving storms may escape the mitigating influence of the GCM-projected tropical upper-tropospheric warming maximum. It is not possible to fully address this question with a single ET case study, but we offer a brief comparison nevertheless. Using high-resolution models, Knutson et al. (2010) 
found maximum wind speed increases from $\sim 2 \%$ to $\sim 11 \%$ for TCs in the late twenty-first century. We find ensemble mean maximum wind speed increases of $\sim 12 \%$ in the realistic orography experiments and $\sim 24 \%$ in partially idealized experiments. The idealized modeling study of Hill and Lackmann (2011) found decreases in minimum SLP of $\sim 10 \mathrm{hPa}$ by the late twentyfirst century. The future ensemble mean SLP deficit increases by $\sim 23 \mathrm{hPa}$ in our simulations. Though more cases must be examined, these initial results are consistent with the hypothesis that transitioning TCs may exhibit greater relative strengthening with warming relative to those remaining in the tropics.

The results demonstrate that the ET of Hurricane Irene in a warmer environment would feature greater TC intensity and a slower transition. Of our main results, the finding of increased duration of ET, substantially heavier precipitation, and greater ET intensity are more likely to hold generally when studying additional cases. The additional deepening late in the life cycle for the future Irene event is likely to be more specific to this particular synoptic environment, and is less likely to be generally relevant. Thus, we recognize that this study is only an initial step toward a complete understanding of the potential changes in ET in a warming climate, and that studies of many additional ET cases are needed in order to form a comprehensive understanding of changes and impacts of ET with climate warming.

Acknowledgments. This research was supported by National Science Foundation (NSF) Grant AGS-1546743, awarded to North Carolina State University. The WRF model was made available by NCAR, which is sponsored by NSF. Model simulations were performed on the Cheyenne and Yellowstone machine of the NCAR Computer and Information System Lab (CISL). The CPC U.S. Unified Precipitation data used for the presentday precipitation evaluation were provided by the NOAA/ OAR/ESRL PSD, Boulder, Colorado, USA. Figures for this paper were created using NCL software package from CISL at NCAR. We thank the Program for Climate Model Diagnosis and Intercomparison (PCMDI) for collecting and archiving the CMIP5 model output. We are indebted to Drs. Walt Robinson and Anantha Aiyyer for providing valuable suggestions on an earlier version of this manuscript.

\section{REFERENCES}

Abraham, J., J. W. Strapp, C. Fogarty, and M. Wolde, 2004: Extratropical transition of Hurricane Michael: An aircraft investigation. Bull. Amer. Meteor. Soc., 85, 1323-1339, https:// doi.org/10.1175/BAMS-85-9-1323.
Agusti-Panareda, A., C. D. Thorncroft, G. C. Craig, and S. L. Gray, 2004: The extratropical transition of Hurricane Irene (1999): A potential-vorticity perspective. Quart. J. Roy. Meteor. Soc., 130, 1047-1074, https://doi.org/10.1256/qj.02.140.

Aiyyer, A., 2015: Recurving western North Pacific tropical cyclones and midlatitude predictability. Geophys. Res. Lett., $\mathbf{4 2}$, 7799-7807, https://doi.org/10.1002/2015GL065082.

Allen, M. R., and W. J. Ingram, 2002: Constraints on future changes in climate and the hydrologic cycle. Nature, 419, 224-232, https://doi.org/10.1038/nature01092.

Ancell, B. C., A. Bogusz, M. J. Lauridsen, and C. J. Nauert, 2018: Seeding chaos: The dire consequences of numerical noise in NWP perturbation experiments. Bull. Amer. Meteor. Soc., 99, 615-628, https://doi.org/10.1175/BAMS-D-17-0129.1.

Archambault, H. M., L. F. Bosart, D. Keyser, and J. M. Cordeira, 2013: A climatological analysis of the extratropical flow response to recurving western North Pacific tropical cyclones. Mon. Wea. Rev., 141, 2325-2346, https://doi.org/10.1175/ MWR-D-12-00257.1.

—, D. Keyser, L. F. Bosart, C. A. Davis, and J. M. Cordeira, 2015: A composite perspective of the extratropical flow response to recurving western North Pacific tropical cyclones. Mon. Wea. Rev., 143, 1122-1141, https://doi.org/10.1175/MWR-D-14-00270.1.

Atallah, E. H., and L. F. Bosart, 2003: The extratropical transition and precipitation distribution of Hurricane Floyd (1999). Mon. Wea. Rev., 131, 1063-1081, https://doi.org/10.1175/15200493(2003)131<1063:TETAPD > 2.0.CO;2.

,,-- and A. R. Aiyyer, 2007: Precipitation distribution associated with landfalling tropical cyclones over the eastern United States. Mon. Wea. Rev., 135, 2185-2206, https:// doi.org/10.1175/MWR3382.1.

Avila, L. A., and J. Cangialosi, 2011: Tropical cyclone report, Hurricane Irene, 21-28 August 2011. National Hurricane Center, 45 pp., http://www.nhc.noaa.gov/data/tcr/AL092011_Irene.pdf.

Bender, M. A., T. R. Knutson, R. E. Tuleya, J. J. Sirutis, G. A. Vecchi, S. T. Garner, and I. M. Held, 2010: Modeled impact of anthropogenic warming on the frequency of intense Atlantic hurricanes. Science, 327, 454-458, https://doi.org/10.1126/science. 1180568.

Bengtsson, L., K. I. Hodges, M. Esch, N. Keenlyside, L. Kornblueh, J.-J. Luo, and T. Yamagata, 2007: How may tropical cyclones change in a warmer climate? Tellus, 59A, 539-561, https:// doi.org/10.1111/j.1600-0870.2007.00251.x.

Beven, J. L., 2012a: RGB airmass imagery: A new tool to diagnose extratropical transition of tropical cyclones. Proc. Fourth Int. Workshop on Extratropical Transition, Sainte-Adele, Quebec, Canada, World Meteorological Organization, 4.1, https:// www.mcgill.ca/meteo/files/meteo/4_1_beven.pdf.

- 2012b: An update on verification of NHC forecasts of extratropical transition. Proc. Fourth Int. Workshop on Extratropical Transition, Sainte-Adele, Quebec, Canada, World Meteorological Organization, 8.1, https://www.mcgill.ca/meteo/ files/meteo/8_1_beven_et_al.pdf.

Bosart, L. F., and G. M. Lackmann, 1995: Postlandfall tropical cyclone reintensification in a weakly baroclinic environment: A case study of Hurricane David (September 1979). Mon. Wea. Rev., 123, 3268-3291, https://doi.org/10.1175/15200493(1995)123<3268:PTCRIA > 2.0.CO;2.

Braun, S. A., 2006: High-resolution simulation of Hurricane Bonnie (1998). Part II: Water budget. J. Atmos. Sci., 63, 43-64, https://doi.org/10.1175/JAS3609.1.

— , and W.-K. Tao, 2000: Sensitivity of high-resolution simulations of Hurricane Bob (1991) to planetary boundary layer 
parameterizations. Mon. Wea. Rev., 128, 3941-3961, https:// doi.org/10.1175/1520-0493(2000)129<3941:SOHRSO > 2.0.CO;2.

Chen, M., W. Shi, P. Xie, V. B. S. Silva, V. E. Kousky, R. W. Higgins, and J. E. Janowiak, 2008: Assessing objective techniques for gauge-based analyses of global daily precipitation. J. Geophys. Res., 113, D04110, https://doi.org/10.1029/ 2007JD009132.

Colle, B. A., 2003: Numerical simulations of the extratropical transition of Floyd (1999): Structural evolution and responsible mechanisms for the heavy rainfall over the northeast United States. Mon. Wea. Rev., 131, 2905-2926, https://doi.org/10.1175/ 1520-0493(2003)131<2905:NSOTET>2.0.CO;2.

Davis, C., and L. F. Bosart, 2002: Numerical simulations of the genesis of Hurricane Diana (1984). Part II: Sensitivity of track and intensity prediction. Mon. Wea. Rev., 130, 1100-1124, https://doi.org/10.1175/1520-0493(2002)130<1100: NSOTGO $>2.0 . \mathrm{CO} ; 2$.

DiMego, M., and L. F. Bosart, 1982: The transformation of tropical storm Agnes into an extratropical cyclone. Part I: The observed fields and vertical motion computations. Mon. Wea Rev., 110, 385-411, https://doi.org/10.1175/1520-0493(1982) $110<0385$ :TTOTSA $>2.0$. CO; 2 .

Emanuel, K. A., 1988: The maximum intensity of hurricanes. J. Atmos. Sci., 45, 1143-1155, https://doi.org/10.1175/15200469(1988)045<1143:TMIOH > 2.0.CO;2.

Evans, C., and Coauthors, 2017: The extratropical transition of tropical cyclones. Part I: Cyclone evolution and direct impacts. Mon. Wea. Rev., 145, 4317-4344, https://doi.org/10.1175/ MWR-D-17-0027.1.

Evans, J. L., and R. E. Hart, 2003: Objective indicators of the life cycle evolution of extratropical transition for Atlantic tropical cyclones. Mon. Wea. Rev., 131, 909-925, https://doi.org/ 10.1175/1520-0493(2003)131<0909:OIOTLC >2.0.CO;2.

Frei, C., C. Schär, D. Lüthi, and H. C. Davies, 1998: Heavy precipitation processes in a warmer climate. Geophys. Res. Lett., 25, 1431-1434, https://doi.org/10.1029/98GL51099.

Galarneau, T. J., C. A. Davis, and M. A. Shapiro, 2013: Intensification of Hurricane Sandy (2012) through extratropical warm core seclusion. Mon. Wea. Rev., 141, 4296-4321, https:// doi.org/10.1175/MWR-D-13-00181.1.

Gentry, M. S., and G. M. Lackmann, 2010: Sensitivity of simulated tropical cyclone structure and intensity to horizontal resolution. Mon. Wea. Rev., 138, 688-704, https://doi.org/10.1175/ 2009MWR2976.1.

Grams, C. M., S. C. Jones, and C. A. Davis, 2013b: The impact of Typhoon Jangmi (2008) on the midlatitude flow. Part II: Downstream evolution. Quart. J. Roy. Meteor. Soc., 139, 2165 2180, https://doi.org/10.1002/qj.2119.

Harr, P. A., and J. M. Dea, 2009: Downstream development associated with the extratropical transition of tropical cyclones over the western North Pacific. Mon. Wea. Rev., 137, 12951319, https://doi.org/10.1175/2008MWR2558.1.

—_, and H. M. Archambault, 2016: Dynamics, predictability, and high-impact weather associated with the extratropical transition of tropical cyclones. Dynamics and Predictability of Large-Scale High-Impact Weather and Climate Events, J. Li et al., Eds., Cambridge University Press, 153-167, https:// doi.org/10.1017/CBO9781107775541.013.

Hart, R. E., 2003: A cyclone phase space derived from thermal wind and thermal asymmetry. Mon. Wea. Rev., 131, 585-616, https:// doi.org/10.1175/1520-0493(2003)131<0585:ACPSDF>2.0.CO;2.
- and J. L. Evans, 2001: A climatology of the extratropical transition of Atlantic tropical cyclones. J. Climate, 14, 546-564, https:// doi.org/10.1175/1520-0442(2001)014<0546:ACOTET>2.0.CO;2.

- , - and C. Evans, 2006: Synoptic composites of the extratropical transition life cycle of North Atlantic tropical cyclones: Factors determining post transition evolution. Mon. Wea. Rev., 134, 553-578, https://doi.org/10.1175/MWR3082.1.

Hazeleger, W., B. J. J. M. Van den Hurk, E. Min, G. J. Van Oldenborgh, A. C. Petersen, D. A. Stainforth, E. Vasileiadou, and L. A. Smith, 2015: Tales of future weather. Nat. Climate Change, 5, 107-113, https://doi.org/10.1038/nclimate2450.

Hill, K. A., and G. M. Lackmann, 2009a: Analysis of idealized tropical cyclone simulations using the Weather Research and Forecasting model: Sensitivity to turbulence parameterization and grid spacing. Mon. Wea. Rev., 137, 745-765, https:// doi.org/10.1175/2008MWR2220.1.

- , and - 2009b: Influence of environmental humidity on tropical cyclone size. Mon. Wea. Rev., 137, 3294-3315, https:// doi.org/10.1175/2009MWR2679.1.

— , and - 2011: The impact of future climate change on TC intensity and structure: A downscaling approach. J. Climate, 24, 4644-4661, https://doi.org/10.1175/2011JCLI3761.1.

Jones, S. C., and Coauthors, 2003: The extratropical transition of tropical cyclones: Forecast challenges, current understanding, and future directions. Wea. Forecasting, 18, 10521092, https://doi.org/10.1175/1520-0434(2003)018<1052: TETOTC $>2.0 . \mathrm{CO} ; 2$.

Jung, C.-Y., H.-J. Shin, C. J. Jang, and H.-J. Kim, 2015: Projected changes in East Asian summer monsoon by dynamical downscaling: Moisture budget analysis. Asia-Pac. J. Atmos. Sci., 51, 77-89, https://doi.org/10.1007/s13143-015-0061-x.

Keller, J. H., 2017: Amplification of the downstream wave train during extratropical transition: Sensitivity studies. Mon. Wea. Rev., 145, 1529-1548, https://doi.org/10.1175/MWR-D-16-0193.1.

_ S. C. Jones, and P. A. Harr, 2014: An eddy kinetic energy view of physical and dynamical processes in distinct forecast scenarios for the extratropical transition of two tropical cyclones. Mon. Wea. Rev., 142, 2751-2771, https://doi.org/ 10.1175/MWR-D-13-00219.1.

- and Coauthors, 2019: The extratropical transition of tropical cyclones. Part II: Interaction with the midlatitude flow, downstream impacts, and implications for predictability. Mon. Wea. Rev., 147, 1077-1106, https://doi.org/10.1175/MWRD-17-0329.1.

Kitabatake, N., 2008: Extratropical transition of tropical cyclones in the western North Pacific: Their frontal evolution. Mon. Wea. Rev., 136, 2066-2090, https://doi.org/10.1175/2007MWR1958.1.

_ 2011: Climatology of extratropical transition of tropical cyclones in the western North Pacific defined by using cyclone phase space. J. Meteor. Soc. Japan, 89, 309-325, https://doi.org/ 10.2151/jmsj.2011-402.

Klein, P. M., P. A. Harr, and R. L. Elsberry, 2000: Extratropical transition of western North Pacific tropical cyclones: An overview and conceptual model of the transformation stage. Wea. Forecasting, 15, 373-395, https://doi.org/10.1175/15200434(2000)015<0373:ETOWNP > 2.0.CO;2.

,-- , and -2002 : Extratropical transition of western North Pacific tropical cyclones: Midlatitude contributions to intensification. Mon. Wea. Rev., 130, 2240-2259, https://doi.org/10.1175/ 1520-0493(2002)130<2240:ETOWNP>2.0.CO;2.

Knutson, T. R., and R. E. Tuleya, 1999: Increased hurricane intensities with $\mathrm{CO}_{2}$-induced warming as simulated using the 
GFDL hurricane prediction system. Climate Dyn., 15, 503519, https://doi.org/10.1007/s003820050296.

, and - 2004: Impact of $\mathrm{CO}_{2}$-induced warming on simulated hurricane intensity and precipitation: Sensitivity to the choice of climate model and convective parameterization. J. Climate, 17, 3477-3495, https://doi.org/10.1175/15200442(2004)017<3477:IOCWOS>2.0.CO;2.

,,-- W. Shen, and I. Ginis, 2001: Impact of $\mathrm{CO}_{2}$-induced warming on hurricane intensities as simulated in a hurricane model with ocean coupling. J. Climate, 14, 2458-2468, https:// doi.org/10.1175/1520-0442(2001)014<2458:IOCIWO>2.0.CO;2.

- and Coauthors, 2010: Tropical cyclones and climate change. Nat. Geosci., 3, 157-163, https://doi.org/10.1038/ngeo779.

Kossin, J. P., K. A. Emanuel, and G. A. Vecchi, 2014: The poleward migration of the location of tropical cyclone maximum intensity. Nature, 509, 349-352, https://doi.org/10.1038/nature13278.

Lackmann, G. M., 2013: The south-central U.S. flood of May 2010: Present and future. J. Climate, 26, 4688-4709, https://doi.org/ 10.1175/JCLI-D-12-00392.1.

_- 2015: Hurricane Sandy before 1900, and after 2100. Bull. Amer. Meteor. Soc., 96, 547-560, https://doi.org/10.1175/ BAMS-D-14-00123.1.

Landsea, C. W., and J. L. Franklin, 2013: Atlantic hurricane database uncertainty and presentation of a new database format. Mon. Wea. Rev., 141, 3576-3592, https://doi.org/10.1175/ MWR-D-12-00254.1.

Lindzen, R. S., and B. Farrell, 1980: A simple approximate result for the maximum growth rate of baroclinic instabilities. J. Atmos. Sci., 37, 1648-1654, https://doi.org/10.1175/15200469(1980)037<1648:ASARFT>2.0.CO;2.

Liu, M., and J. A. Smith, 2016: Extreme rainfall from landfalling tropical cyclones in the eastern United States: Hurricane Irene (2011). J. Hydrometeor., 17, 2883-2904, https://doi.org/10.1175/ JHM-D-16-0072.1.

— G. A. Vecchi, J. A. Smith, and H. Murakami, 2017: The present-day simulation and twenty-first-century projection of the climatology of extratropical transition in the North Atlantic. J. Climate, 30, 2739-2756, https://doi.org/10.1175/ JCLI-D-16-0352.1.

Lloyd, E. A., and N. Oreskes, 2018: Climate change attribution: When is it appropriate to accept new methods? Earth's Future, 6, 311-325, https://doi.org/10.1002/2017EF000665.

Lynch, P., and X. Y. Huang, 1992: Initialization of the HIRLAM model using a digital filter. Mon. Wea. Rev., 120, 1019-1034, https:// doi.org/10.1175/1520-0493(1992)120<1019:IOTHMU>2.0.CO;2.

Mallard, M. S., G. M. Lackmann, A. Aiyyer, and K. A. Hill, 2013: Atlantic hurricanes and climate change. Part I: Experimental design and isolation of thermodynamic effects. J. Climate, 26, 4876-4893, https://doi.org/10.1175/JCLI-D-12-00182.1.

Marciano, C. G., G. M. Lackmann, and W. A. Robinson, 2015: Changes in U.S. East Coast cyclone dynamics with climate change. J. Climate, 28, 468-484, https://doi.org/10.1175/JCLID-14-00418.1.

Meinshausen, M., and Coauthors, 2011: The RCP greenhouse gas concentrations and their extensions from 1765 to 2300 . Climatic Change, 109, 213-241, https://doi.org/10.1007/s10584-011-0156-z.

Mizuta, R., O. Arakawa, T. Ose, S. Kusunoki, H. Endo, and A. Kitoh, 2014: Classification of CMIP5 future climate responses by the tropical sea surface temperature changes. SOLA, 10, 167-171, https://doi.org/10.2151/sola.2014-035.

Möller, J. D., and M. T. Montgomery, 2000: Tropical cyclone evolution via potential vorticity anomalies in a three-dimensional balance model. J. Atmos. Sci., 57, 3366-3387, https://doi.org/10.1175/15200469(2000)057<3366:TCEVPV>2.0.CO;2.

Murakami, H., 2014: Tropical cyclones in reanalysis data sets. Geophys. Res. Lett., 41, 2133-2141, https://doi.org/10.1002/ 2014GL059519.

Neale, R. B., and B. J. Hoskins, 2000: A standard test for AGCMs including their physical parameterizations: I: The proposal. Atmos. Sci. Lett., 1, 101-107, https://doi.org/10.1006/asle.2000.0019.

Oouchi, K., J. Yoshimura, H. Yoshimura, R. Mizuta, S. Kusunoki, and A. Noda, 2006: Tropical cyclone climatology in a global warming climate as simulated in a $20 \mathrm{~km}$-mesh global atmospheric model: Frequency and wind intensity analyses. J. Meteor. Soc. Japan, 84, 259-276, https://doi.org/10.2151/ jmsj.84.259.

Quinting, J. F., and S. C. Jones, 2016: On the impact of tropical cyclones on Rossby wave packets: A climatological perspective. Mon. Wea. Rev., 144, 2021-2048, https://doi.org/10.1175/ MWR-D-14-00298.1.

Rasmussen, R., and Coauthors, 2011: High-resolution coupled climate runoff simulations of seasonal snowfall over Colorado: A process study of current and warmer climate. J. Climate, $\mathbf{2 4}$ 3015-3048, https://doi.org/10.1175/2010JCLI3985.1.

Ritchie, E. A., and R. L. Elsberry, 2003: Simulations of the extratropical transition of tropical cyclones: Contributions by the midlatitude upper-level trough to re-intensification. Mon. Wea. Rev., 131, 2112-2128, https://doi.org/10.1175/1520-0493(2003) $131<2112:$ SOTETO $>2.0$. CO; 2 .

Saha, S., and Coauthors, 2014: The NCEP Climate Forecast System version 2. J. Climate, 27, 2185-2208, https://doi.org/10.1175/ JCLI-D-12-00823.1.

Sato, T., F. Kimura, and A. Kitoh, 2007: Projection of global warming onto regional precipitation over Mongolia using a regional climate model. J. Hydrol., 333, 144-154, https:// doi.org/10.1016/j.jhydrol.2006.07.023.

Shen, W., R. E. Tuleya, and I. Ginis, 2000: A sensitivity study of the thermodynamic environment on GFDL model hurricane intensity: Implications for global warming. J. Climate, 13, 109-121, https://doi.org/10.1175/1520-0442(2000)013<0109: ASSOTT>2.0.CO;2.

Shepherd, T. G., 2016: A common framework for approaches to extreme event attribution. Curr. Climate Change Rep., 2, 2838, https://doi.org/10.1007/s40641-016-0033-y.

Shin, J. H., and D.-L. Zhang, 2017: The impact of moist frontogenesis and tropopause undulation on the intensity, size, and structural changes of Hurricane Sandy (2012). J. Atmos. Sci., 74, 893-913, https://doi.org/10.1175/JAS-D-15-0362.1.

Sinclair, M. R., 1993: Synoptic-scale diagnosis of the extratropical transition of a southwest Pacific tropical cyclone. Mon. Wea. Rev., 121, 941-960, https://doi.org/10.1175/1520-0493(1993) $121<0941$ :SSDOTE $>2.0$. CO;2.

- 2002: Extratropical transition of southwest Pacific tropical cyclones. Part I: Climatology and mean structure changes. Mon. Wea. Rev., 130, 590-609, https://doi.org/10.1175/15200493(2002)130<0590:ETOSPT>2.0.CO;2.

Skamarock, W. C., and Coauthors, 2008: A description of the Advanced Research WRF version 3. NCAR Tech. Note NCAR/TN-475+STR, 113 pp.

Soden, B. J., D. L. Jackson, V. Ramaswamy, D. Schwarzkopf, and $\mathrm{X}$. Huang, 2005: The radiative signature upper tropospheric moistening. Science, 310, 841-844, https://doi.org/10.1126/ science.1115602.

Taniguchi, K. 2018: A simple ensemble simulation technique for assessment of future variations in specific high-impact weather 
events. J. Geophys. Res. Atmos., 123, 3343-3461, https:// doi.org/10.1002/2017JD027928.

Trenberth, K. E., L. Smith, T. Qian, A. Dai, and J. Fasullo, 2007: Estimates of the global water budget and its annual cycle using observational and model data. J. Hydrometeor., 8, 758-769, https://doi.org/10.1175/JHM600.1.

- J. T. Fasullo, and T. G. Shepherd, 2015: Attribution of climate extreme events. Nat. Climate Change, 5, 725-730, https:// doi.org/10.1038/nclimate2657.

Vecchi, G. A., and B. J. Soden, 2007: Increased tropical Atlantic wind shear in model projections of global warming. Geophys. Res. Lett., 34, L08702, https://doi.org/10.1029/2006GL028905.
Wang, Y., 2002: Vortex Rossby waves in a numerically simulated tropical cyclone. Part I: Overall structure, potential vorticity, and kinetic energy budgets. J. Atmos. Sci., 59, 1213-1238, https://doi.org/10.1175/1520-0469(2002)059<1213:VRWIAN > 2.0.CO;2.

Wentz, F. J., L. Ricciardulli, K. Hilburn, and C. Mears, 2007: How much more rain will global warming bring? Science, 317, 233235, https://doi.org/10.1126/science.1140746.

Xie, P., A. Yatagai, M. Chen, T. Hayasaka, Y. Fukushima, C. Liu, and S. Yang, 2007: A gauge-based analysis of daily precipitation over East Asia.J. Hydrometeor., 8, 607-626, https:// doi.org/10.1175/JHM583.1. 